\title{
The echolocation calls, habitat relationships, foraging niches and communities of Pilbara microbats
}

\author{
N.L. McKenzie ${ }^{1}$ and R.D. Bullen ${ }^{2}$ \\ ${ }^{1}$ Department of Environment and Conservation, PO Box 51, Wanneroo, Western Australia 6946, \\ Australia. Email: normm@dec.wa.gov.au \\ ${ }^{2} 43$ Murray Drive, Hillarys, Western Australia 6025, Australia
}

\begin{abstract}
Between 2004 and 2007, we systematically surveyed microbats across the Pilbara region in Western Australia, and collected data on species' foraging ecology. Here we report the results of the echolocation survey of 69 sites dispersed among 24 survey areas covering the $179,000 \mathrm{~km}^{2}$ region. Echolocation call sequences were identified using a library of known calls accumulated during field work. In combination, the frequency maintained for the greatest number of cycles $\left(F_{\text {peak }}\right)$ and the bandwidth ratio of this peak $(Q)$ identified search-mode echolocation calls by 13 of the 17 species comprising the microbat fauna of the Pilbara bioregion. These variables did not separate Taphozous georgianus from T. hilli calls, Chalinolobus gouldii from Mormopterus loriae, and allopatric pairs of Nyctophilus species. Even so, the spectral characters provided an ecologically informative, viable and non-intrusive survey tool.

The survey revealed two compositionally distinct communities. One comprised 14 species and occupied landward environments, while the other comprised 9 species and occupied mangroves. Three members of the mangrove community were confined to mangroves (M. loriae, Nyctophilus arnhemensis and N. geoffroyi pallescens), being replaced by allopatric congenerics in the region's landward environments (Mormopterus beccarii, Nyctophilus bifax daedalus and N. g. geoffroyi). In both communities, the searchmode calls of syntopic species were dispersed in spectral space, showed only peripheral overlap in their spectral variables $\left(Q\right.$ and $\left.F_{\text {peak }}\right)$ and were arrayed according to differences in foraging niche determined from empirical data on species' flight capabilities and foraging behaviours. These observations imply
\end{abstract} a niche-assembly model of metacommunity structure.

However, on its own, this model was insufficient to explain the composition of the Pilbara microbat assemblages. Nestedness was observed in assemblage composition that could be explained by environmental factors, implying the influence of environmental controls. The richest microbat assemblages were recorded in well-developed riparian environments with complex vegetation structures and permanent pools that were set in cavernous landscapes. Two species (Nyctophilus bifax and Chalinolobus morio) were restricted to these productive riparian environments, while two others (Macroderma gigas and Rhinonicteris aurantia) were found to be more common than previously supposed despite detectability constraints caused by their cryptic calls. The widespread occurrence of $M$. gigas and $R$. aurantia is reasonable because caves and mines are common in the ranges of the Pilbara region, and offer physiologically favourable day-roosts to these otherwise mesic tropical species. Proximity of cavernous landscapes also explained the presence or absence of other obligate cave/rock-crevice roosting species in assemblages (Taphozous spp., and Vespadelus finlaysoni).

Comparison with surrounding regions revealed a diversity-productivity model of faunal structure, with an organisation that conforms to the specialisation hypothesis in which co-occurring species occupy different foraging niches. Three riparian sites (Turee Creek, Cattle Gorge and Weeli Wolli) and four mangrove stands are identified for reservation.

Key Words: bat, echolocation, F composition, habitat relationships

Q6dB, metacommunity, species 


\section{INTRODUCTION}

A conservation reserve system that 'captures' each species once is not enough to ensure the persistence of ecosystem complexity. Given the dynamic nature of ecosystem processes and landscape disturbance regimes, an understanding of the factors structuring communities, especially those that determine differences in species composition point-to-point across landscapes, is fundamental to reserve system design. It also contributes to effective off-reserve conservation.

Foraging method has proved to be an important mechanism of resource allocation in communities (e.g. Hespenheide 1975; McKenzie and Rolfe 1986; Simberloff and Dyan 1991). In bats, foraging method is tightly coupled to aspects of their flight morphology and echolocation call structure. In these terms, niche-assembly models of metacommunity structure related to resource partitioning have been documented previously for microbat communities of north-western Australia, including the Little Sandy Desert community (McKenzie et al. 2002) and those of mangrove stands along the Kimberley and Pilbara coasts (McKenzie and Rolfe 1986; McKenzie and Start 1989), but there has been no investigation of factors influencing differences in assemblage composition within these microbat communities from place to place.

The echolocation calls that microbats emit are reasonably stereotyped, but vary across species according to the characteristics of their different foraging niches (Neuweiler 1990). Within a species, apparent variation in sonar design can be related to differences between individuals and between populations (e.g. Parsons 1997; Barclay et al. 1999; Murray et al. 2001), to Doppler effects (e.g. Guppy and Coles 1988), to signal recording and analysis techniques (Parsons et al. 2000), to habitat differences and presence of conspecifics (Obrist 1995), and to the foraging context in which a bat is emitting calls including the 'search', 'approach' and 'interception' phases in call sequences (e.g. Griffin et al. 1960; Schnitzler et al. 1987; Kalko and Schnitzler 1993). Search-mode calls are useful for acoustic identification of species (e.g. O'Farrell et al. 1999; Murray et al. 2001; Bullen and McKenzie 2002a). They are prominent above background noise levels and, by measuring call repetition rates, can be uniquely discriminated from other phases of call sequences, thereby reducing the variability problem.

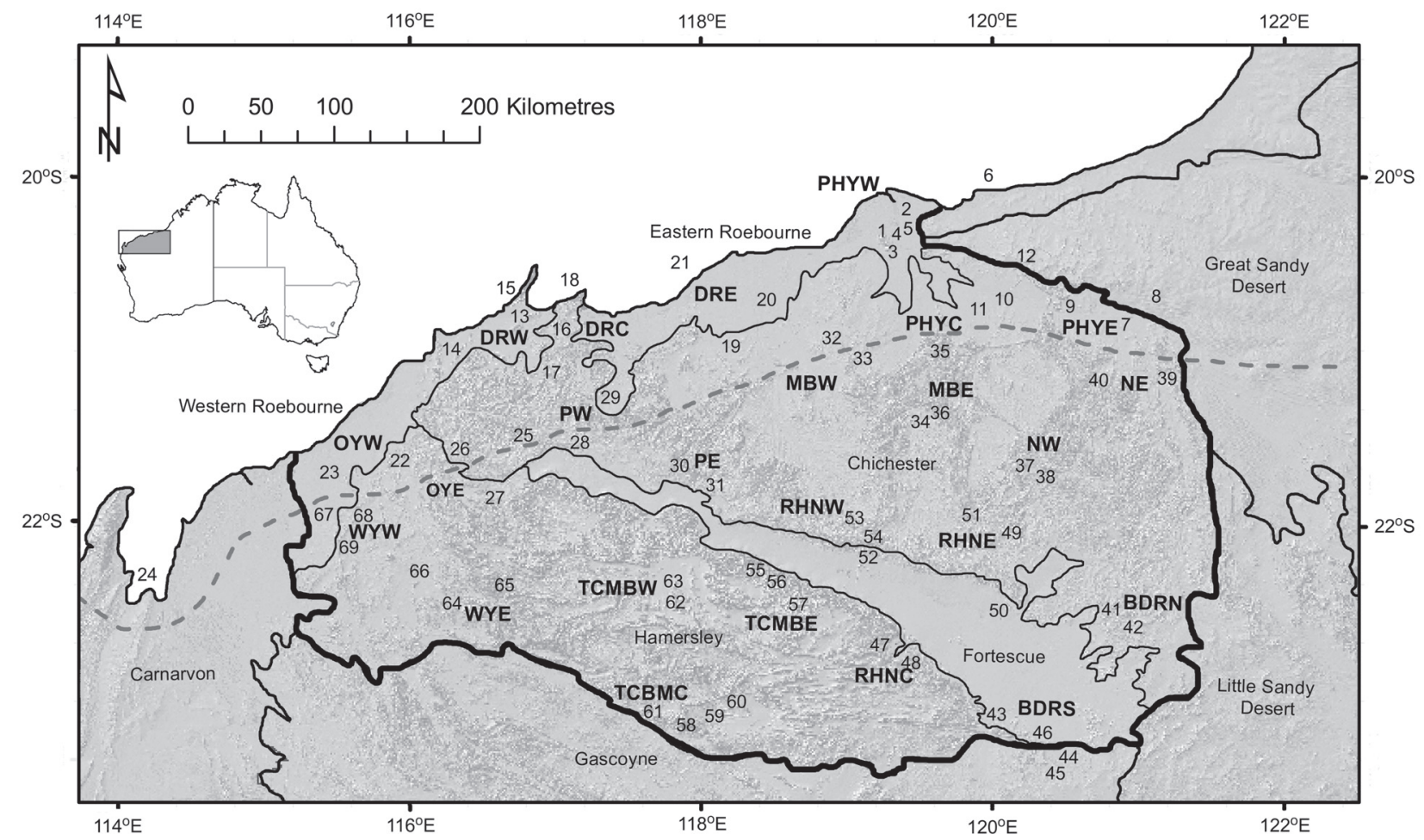

Figure 1 The Pilbara biogeographic region (outlined in bold) showing the boundaries of its four IBRA sub-regions (Environment Australia 2000), the surrounding regions, the 69 sites sampled for microbats during the survey (numbered 1 to 69), the codes for the 24 survey areas (e.g. PHNW), and the boundary between its two bioclimatic zones (dashed line). These are superimposed on a digital elevation model (after Geoscience Australia GEODATA 3 second DEM version 2). 
In this paper we use spectral analysis in frequency domain (Bullen and McKenzie 2002a; McKenzie and Bullen 2003) to characterise and differentiate the search-mode echolocation calls of microbat species from the Pilbara Bioregion of Western Australia, and develop a call dictionary. Using this dictionary, we identify bat call sequences recorded during an echolocation survey of the region, display the composition of the Pilbara microbat fauna in terms of species co-occurrence patterns, then explore compositional patterns in terms of environmental factors.

To provide a context on metacommunity structure, we also document the foraging niches of Pilbara microbats in terms of differences in their flight capabilities, foraging microhabitats and foraging strategies. Since observations on species foraging niche are scarce for most Australian bats, our field program focused on collecting these data, and we report them in detail.

\section{METHODS}

\section{Study area and fauna}

The Pilbara biogeographic region has an area of $179,000 \mathrm{~km}^{2}$ (Figure 1), and corresponds closely with the Pilbara Craton. It straddles two bioclimatic zones (Beard, 1990). The broad near-coastal band has a semidesert tropical climate with 9 to 11 months of dry weather, and summer rainfall. The rest of the region has a desert climate with summer rain, characterised by up to 12 months of dry weather and generally higher temperatures. Average annual rainfall is $290 \mathrm{~mm}$, but locally unreliable, while average maximum temperatures range from $25.3^{\circ} \mathrm{C}$ in July to $37.8^{\circ} \mathrm{C}$ in January, and minimum night time temperatures range from $11.8^{\circ} \mathrm{C}$ in July to $25.2^{\circ} \mathrm{C}$ in January.

The region is divided into four geomorphically distinctive IBRA subregions - Chichester, Fortescue, Hamersley and Roebourne (Figure 1). All are drained by seasonally active river systems that are fringed by large gum trees with frequent hollow branches and, in some areas, by tall riparian forests that have developed around permanent pools behind rock-bars or are associated with springs. The north and central parts of the region comprise low open woodlands and grasslands with scattered trees on broad plains that, in places, are interrupted by ranges covered by tree steppe and in which caverns and old underground mines are common. The region's south comprises ranges and plateaux with low woodlands over grasses, and is dissected by gorges. Caves are common along the scarps. Coastal and sub-coastal plains support grasslands with scattered trees, dwarf shrub steppes and low mangrove forests.
The region's microbat fauna includes arid zone populations of four molossids, three emballonurids, eight vespertilionids including four nyctophilinids, one hipposiderid and one megadermatid (Table 1). Nomenclature follows van Dyck and Strahan (2008), although we treat two subspecies of Nyctophilus geoffroyi as distinct (N. g. geoffroyi and N. g. pallescens). These subspecies are distinguished on external and cranial measures presented in Thomas (1913).

\section{Reference call dictionary}

During field work between 1992 and 2007, echolocation call sequences by free-flying bats of known identity were recorded from: (1) bats captured in mist nets or bat traps set over pools, in riparian woodlands, in mangroves or across the entrances of caves and mines, then released with bioluminescent tags (Buchler 1976) and recorded on subsequent passes; (2) bats that we shot while their echolocation calls were being recorded (CALM Animal Ethics Permit No. 14/93); (3) bats from surrounding regions if we were unable to record sequences by at least 10 individuals from the study area. We excluded sequences when echolocation calls by more than one individual were present in the sequence.

Call sequences were recorded using the frequency-division function of Anabat II ultrasound detectors (Titley Electronics, Australia), set to divide by 16 . The frequency-division function using Zerocrossing analysis within these detectors is known to operate on the strongest harmonic present (Parsons et al. 2000), normally the fundamental harmonic. Output was stored directly onto Metal IV cassette tapes using a Sony Walkman Professional (WMD6C) tape recorder and, after 2003, a Sony Minidisc recorder (MZ-N510) in SP-mono mode.

COOL EDIT 2000, now ADOBE AUDITION 2 (Adobe Systems, USA), was used to convert the recordings to '.mp3' files, display call sequences in spectral view, then analyse consistently shaped, regularly spaced, sequential sets of 'search' mode calls with clean, well-defined shape (see McKenzie and Bullen 2003 for details). Unlike the 'approach' or 'interception' phases of sequences, search mode calls are emitted at a rate of one call per wingbeat or fewer (Schnitzler et al. 1987; Kalko and Schnitzler 1993, 1998; McKenzie and Bullen 2003). Since microbat species all flap their wings at similar frequencies (7 to $12 \mathrm{~Hz}$ : Schnitzler et al. 1987; Bullen and McKenzie 2002b), call repetition rates can be used to distinguish periods of 'search mode' in sequences recorded from free-flying bats.

We used COOL EDIT 2000 to carry out a 2048-point Blackmann-Harris fast-Fourier transformation of each search-mode call. This analysis provided the frequency spectrum (profile) 
Table 1 The Pilbara microbat fauna.

\begin{tabular}{l|l|l}
\hline Family & Species & Code \\
\hline Megadermatidae & Macroderma gigas (Dobson, 1880) & $\mathrm{Mg}$ \\
Hipposideridae & Rhinonicteris aurantia Gray, 1845 & $\mathrm{Ra}$ \\
Emballonuridae & Taphozous georgianus Thomas, 1915 & $\mathrm{Tg}$ \\
& Taphozous hilli Kitchener, 1980 & $\mathrm{Th}$ \\
Molossidae & Saccolaimus flaviventris (Peters, 1867) & $\mathrm{Sf}$ \\
& Tadarida australis (Gray, 1838) & $\mathrm{Ta}$ \\
Chaerephon jobensis (Miller, 1902) & $\mathrm{Cj}$ \\
& Mormopterus beccarii Peters, 1881 & $\mathrm{Mb}$ \\
& Mormopterus loriae Thomas, 1897 & $\mathrm{Ml}$ \\
& Nyctophilus arnhemensis Johnson, 1959 & $\mathrm{Na}$ \\
& Nyctophilus bifax daedalus Thomas, 1915 & $\mathrm{Nbd}$ \\
& Nyctophilus geoffroyi geoffroyi Leach, 1821 & $\mathrm{Ngg}$ \\
& Nyctophilus g. pallescens (Thomas, 1913) & $\mathrm{Ngp}$ \\
& Chalinolobus gouldii (Gray, 1841) & Cg \\
& Chalinolobus morio (Gray, 1841) & $\mathrm{Cm}$ \\
& Scotorepens greyii (Gray, 1843) & Sg \\
& Vespadelus finlaysoni (Kitchener, Jones and Caputi, 1987) & Vf \\
\hline
\end{tabular}

of the call's strongest harmonic (Figure 2, modified from McKenzie and Bullen 2003). The frequency that was maintained for the greatest number of cycles $\left(F_{\text {peak }}\right)$ could be determined from the frequency profile. We also measured the quality factor of the strongest harmonic $\left(Q=F_{\text {peak }} /\right.$ bandwidth), an index of sharpness of tuning (Laverghetta 1981). Because of the noise levels associated with field recordings, we measured $Q 6 d B$ (subsequently referred to in this paper as ' $Q$ ') at $50 \%$ of the cycle-count at $F_{\text {peak }}$ (equivalent to $6 \mathrm{~dB}$ below peak from the fast-Fourier transformation), rather than at the $-10 \mathrm{~dB}$ (i.e. $Q 10 \mathrm{~dB}$ ) normally used under laboratory conditions when assessing the frequency tuning properties of auditory neurones (e.g. Casseday and Covey 1992).

\section{Echolocation survey}

Between 2004 and 2007, Anabat II ultrasound detectors connected to minidisc recorders in 'mono, short-play' mode were placed at ground level in 69 sites scattered throughout the Pilbara (Figure 1). The detector's microphone was orientated within $30^{\circ}$ of vertical. Sites were not randomly arrayed; there were two to four sites in each of the 24 survey areas into which the region was divided (McKenzie et al. 2009). Most sites were on watercourses with pools of varying size and permanence, but scree slopes, sandplains, mulga flats and low open woodlands were also sampled (10 sites), along with mangroves (5 sites). Some sites were near caves and abandoned mines. At each site, echolocation calls emitted by passing bats were recorded for an average of $150 \mathrm{~min}$ from late dusk on one or more nights in spring, autumn, winter and/or summer (we averaged 1.9 recording nights totalling $4.5 \mathrm{~h}$ per site). Repeated sampling depended on logistical opportunities offered by a trapping program that focused on ground mammals and reptiles, a constraint that precluded a more systematic sampling regime for bats and any multivariate statistical analysis requiring a balanced sampling design. For this reason, analysis of habitat-use was confined to species presence/absence data at sites, rather than the relative abundance of detections and issues of seasonality (Gannon et al. 2003). Overall sampling efficiency for microbat species was assessed using both the Chao2 (Chao 1987) and the incidence-based (ICE, Lee and Chao 1994) estimators in the EstimateS software (Colwell 2006). $F_{\text {peakc }}$ and $Q$ values were determined for the search-mode calls in the recordings, and identified to species using the reference call data in conjunction with the spectral diagnostics previously published by:

- Bullen and McKenzie (2002a) for Western Australian Nyctophilus spp. (which covered populations of the four Pilbara Nyctophilus 


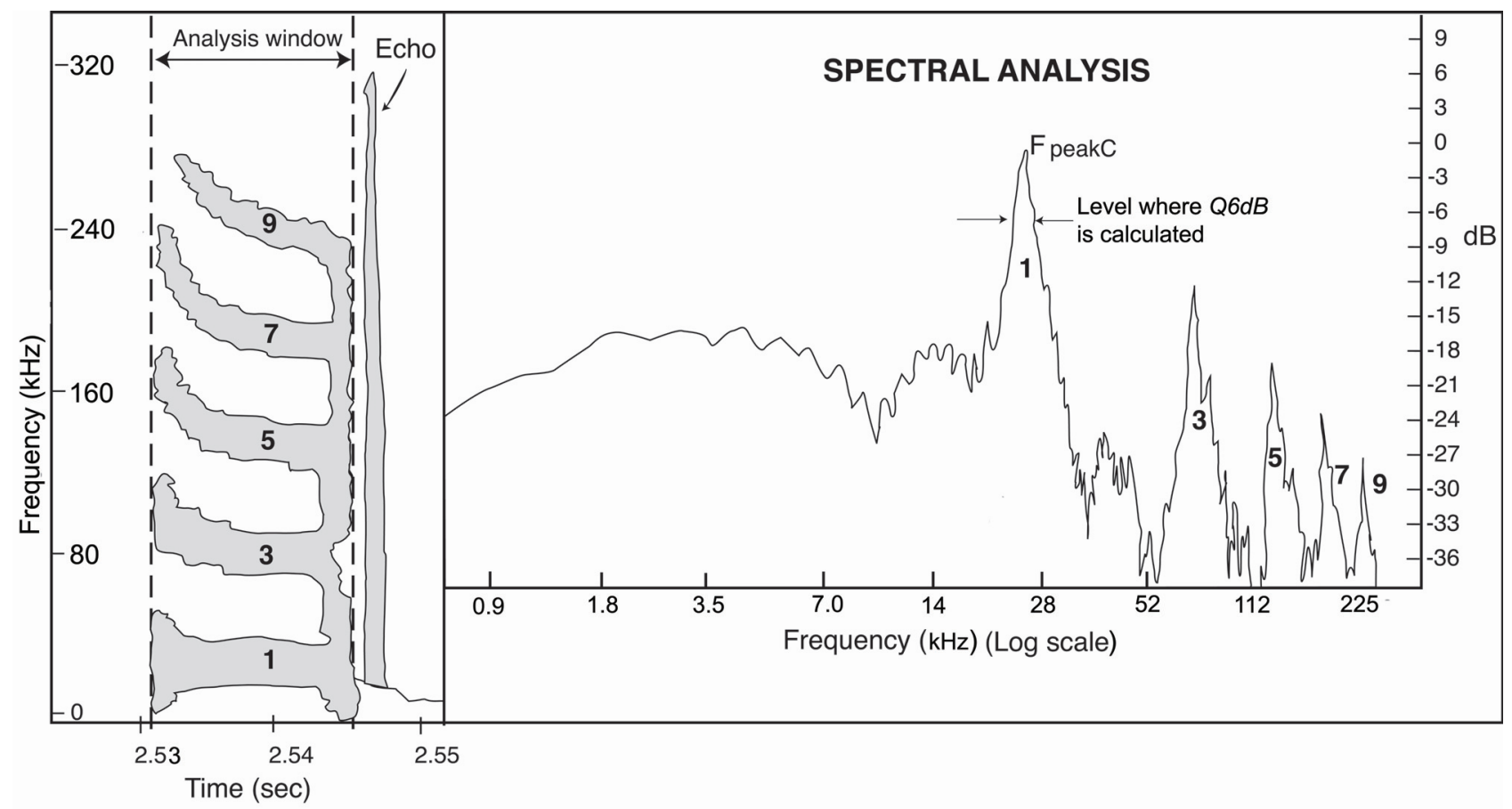

Figure 2 Mormopterus beccarii search mode call recorded using an ANABAT II detector, and displayed in frequencytime domain using COOL EDIT (modified from McKenzie and Bullen 2003). Results of the spectral analysis (frequency profile) of the entire call ('Analysis window') are included on the right-hand side of the figure as

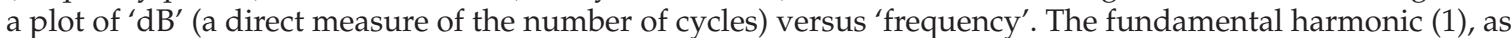
well as higher harmonics ( 3 to 9), are visible in both displays. ANABAT II produces a square-wave output, so these higher harmonics are artifacts produced by COOL EDIT's Fast Fourier Transform routine.

species), and

- McKenzie and Bullen (2003) for discriminating Saccolaimus flaviventris from Chaerephon jobensis, and Taphozous spp. from M. beccarii.

\section{Habitat}

This analysis assumes that spatial distribution reflects an underlying correlation with environmental factors (Austin 1991; Clarke 1993), '... a habitat paradigm' Armstrong (2005), and treats metacommunity relationships (e.g. microhabitat and resource availability hypotheses, sensu Hernandez et al. 2005) as second order effects at regional scales. Because we do not yet have an explicit model to provide an explanatory framework for our results, our interpretation of this inherently exploratory design was based on deductive logic (Oksanen 2001; Dickman and Crowther 2008) and, as no experimental or mensurative design has been implemented to construct a null hypothesis (Austin and McKenzie 1988), alternative hypotheses are not excluded. Inferential statistics are used to test patterns observed in the empirical data.

Numerical clustering analyses from the computer package PATN (Belbin 1995) were used to expose patterns of species composition and species cooccurrence in the site data matrix (species presence/ absence). The Czekanowski measure was used to compare the 69 sites according to their species similarities and Two-step (Belbin 1980) was used to determine the quantitative relationships between species in terms of their co-occurrences. These procedures yielded dissimilarity matrices for sites and species, respectively. Flexible UPGMA (unweighted pair-group mean averaging, Sneath and Sokal 1973; Belbin 1995), with the clustering parameter (Beta) set to -0.1, was used to derive classification partition structures (dendrograms) from both matrices so that the sites could be clustered according to compositional similarities, and species clustered according to co-occurrences. ANOSIM (Clarke and Green 1988) was then used to test if there was a significant difference in the $F$-ratio of the association values between or within classification groups, compared with 100 iterations in which sites were randomly re-allocated between groups.

The species-dendrogram partitions were interpreted in terms of the previously known habitat associations and roost preferences of their component species across their wider distributions in Australia (e.g. van Dyck and Strahan 2008). The site-dendrogram partitions were compared statistically in terms of several environmental attributes of the sites. These attributes were chosen because of their biological relevance as gradients 
Table 2 Category definitions for 'gestalt' environmental attributes listed in Appendix 1.

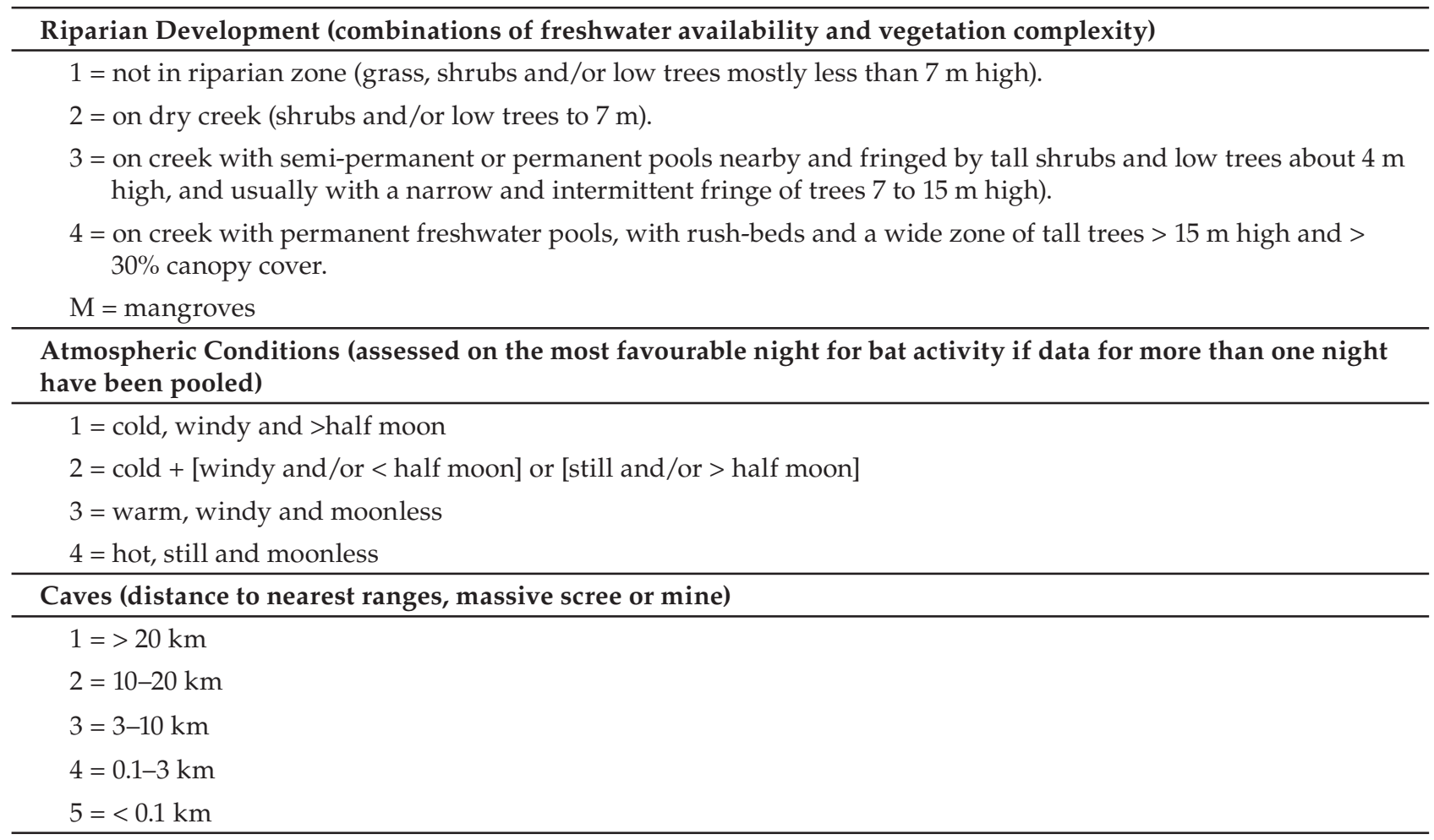

likely to influence microbat distributions, either directly or indirectly, and also on the basis that they were not highly intercorrelated (Spearman Rho $<0.5)$, thereby avoiding multi-collinearity. On these criteria, we retained only two of the climatic attributes, 'minimum temperature in the coolest period annually' and 'annual average precipitation'. These were generated for the sites using ANUCLIM (McMahon et al. 1995). Temperature and rainfall attributes have direct effects on the ecophysiology of many mammal species (e.g. Prosser and Brown 1961; McNab 1980; Spicer and Gaston 1999; Meynard and Quinn 2007). Attributes such as riparian development (combining vegetation complexity and freshwater pool permanence in creeks), distance to coast, distance to ranges (rock crevices, caves and/or underground mines), and atmospheric conditions on the sampling night/s (windiness, cloud cover, moon phase and temperature) were recorded on-site, or derived from Google Earth and from the nearest Bureau of Meteorology weather station (Table 2). Their biological relevance for Australian microbats has been well documented (e.g. McKenzie and Rolfe 1986; Lumsden and Bennett 1995; Law et al. 1998; McKenzie and Muir 2000; Young and Ford 2000; Williams and Dickman 2004; Milne et al. 2005a,b). To determine whether spatial autocorrelation caused by proximity between landward sites should to be treated as a factor influencing composition (e.g.
Diniz-Filho et al. 2003), we plotted compositional dissimilarity (Czekanowski) against Euclidean distance apart $(\mathrm{km})$ for all pairs of sites, then tested for significance in the relationship using 999 randomisations. The matching of environmental to biotic patterns was carried out using group statistics module of PATN (Belbin 1995), and assessed using Kruskall-Wallis one way analysis of variance by ranks.

\section{Foraging niche data for metacommunity analysis}

To quantify aspects of resource partitioning in Pilbara microbat guilds, three aspects of niche were documented: microhabitat, flight speed and turn capability. In addition, data on species' foraging strategies were extracted from relevant literature and supplemented with observations made during the field work. These data were collected to provide a basis for assessing the influence of metacommunity interactions on assemblage composition.

\section{Usual foraging microhabitat}

Microbat records from our fieldwork were assigned to one of four foraging microhabitats, depending on differences in the degree of airspace clutter (obstruction to straight flight) at the point where the free-flying bat was first seen. Observations were made with a spotlight, in the glow of a floodlight or at dusk or when bats 
returned to forage nearby after being released carrying bioluminescent tags ('Cyalume'). They were recorded if the bat was seen to be foraging or if its 'search-approach-interception' echolocation sequences were detected. Nearly half of the microhabitat data came from observations we made while recording ultrasound sequences emitted by bats of, at the time, unknown identity. Microhabitat definitions follow McKenzie et al. (2002), and were modified from McKenzie and Rolfe (1986):

1. Open airspaces more than $5 \mathrm{~m}$ above or beside canopies, cliffs, hill-slopes or hilltops (OC).

2. Semi-open airspaces a few metres above $(>2$ but $<5 \mathrm{~m}$ ) the top of the canopy or bare hills (AC).

3. Semi-cluttered airspaces within a few metres (> 2) of the sides and underside of the canopy or rock faces $(\mathrm{BS} / \mathrm{O})$.

4. Cluttered airspace inside stands of vegetation (IS) or within two metres of foliage, bark, ground or surface of pools (BS/A). IS and BS/A could not be discriminated in the open vegetation of the Pilbara region.

\section{Flight speeds}

These were measured from passing bats, either at dusk as they foraged around vegetation or departed their roosts in caves or abandoned mines, or at night if they were partially illuminated using a 12-V neon floodlight ('Versa-Light' by Burn-Brite Lights, Australia). In such situations they were subsequently identified from their ultrasound sequences. The speeds were measured using a hand-held K-band radar unit (Doppler-shift meter model TS3, supplied by Municipal Electronics, UK), calibrated for a speed range of 1-28 $\mathrm{m} \mathrm{sec}^{-1}$ (4-100 kph). Additional flight speed data were measured from bats released in the field within a few hours of capture carrying bioluminescent tags or released the next morning in daylight. In this case, sub-adults, pregnant females and animals with scarred wings were excluded, as was the period while bats accelerated from rest. All readings for a species were pooled. Mode rather than average speed values were used for our analysis because the readings did not have normal distributions, even when pooled by species. Speed data from individuals captured on the periphery of the adjacent Ashburton and Little Sandy Desert Regions were incorporated to increase sample sizes for four widespread species (M. beccarii, N. geoffroyi, S. flaviventris, T. australis).

\section{Turn capability}

Turn capability, in conjunction with flight speed, provides a basis for rating bat airframes in terms of agility (see Table 10 in Bullen and McKenzie 2001), i.e. the ability to generate roll acceleration and/ or side force when entering and exiting a turn. A manoeuvrable bat has a small radius of turn while an agile bat can enter these tight turns at moderate to high speeds, and can abruptly tighten the radius of its turn. Therefore, by definition, agile bats are inherently manoeuvrable, but manoeuvrable bats are not necessarily agile. Agility is most readily recognised when bats enter and exit level turns at speed so that we can estimate the aerodynamic loading (normal acceleration in the sagittal plane $=\cos (\Phi)^{-1}$, where ' $\Phi^{\prime}$ ' is the bank angle). During these turns, agile bats can roll quickly to bank angles that exceed $70^{\circ}$ ( $>2.9$ gravities; Bullen and McKenzie 2001) so that turns appear abrupt rather than radiused. Tight wing-overs, stall-turns, half hammer heads and flick rolls induce airframe loadings quickly, equal to or greater than those generated during $70^{\circ}$ or $80^{\circ}$ 'level banking turns', implying agility (airframe loading of 2.9 and 5.8 gravities respectively; Bullen and McKenzie 2001).

Turning manoeuvres were identified using slow motion video recordings of individual bats released to fly around in a large, well-lit room. Rooms chosen as flight chambers had floor areas of between 50 and $60 \mathrm{~m}^{2}$ (7-9 m long, 8-6 m wide, 2.7-3 $\mathrm{m}$ high), large enough to provide all but the largest of the microbats with a considerable margin for manoeuvring (Bullen and McKenzie 2001). Bat flight manoeuvres were filmed using a video camera (Sony Video8 Professional CCD$\mathrm{V} 100 \mathrm{E}$ ) set to 25 frames $\mathrm{s}^{-1}$, so that the types of manoeuvre undertaken by each species could be identified. Observations on the turns used by the large microbats (C. jobensis, M. beccarii, T. australis, $S$. flaviventris and Taphozous spp.) were recorded from free-flying bats in the field while microhabitat and flight-speed data were being collected, and were also available from our previous studies in adjacent regions (e.g. McKenzie et al. 2002). Turn capabilities of the largest microbat (Macroderma gigas) were observed by partially obstructing a bend at the entrance of a day-roost in the abandoned Klondyke Queen Mine from dusk onwards so that emerging M. gigas had to turn back, pitch-upwards to exit through a gap in the tunnel's ceiling, or use a rolling manoeuvre to avoid the obstacle and exit in level flight.

\section{RESULTS}

\section{Call spectral characteristics}

Tables 3 and 4 summarise search-mode echolocation call characteristics of the 17 species (6 families) known from the region, and include statistics on the number of individual bats, call sequences and calls used for characterisation. Three of the species are restricted to the mangrove stands scattered along the Pilbara coast (M. loriae, 
N. g. pallescens and N. arnhemensis; McKenzie and Start 1989). Western Australian Museum and literature records show that all three are replaced by allopatric con-generic counterpart species in the region's landward environments ( $M$. beccarii, N. g. geoffroyi and N. bifax daedalus, respectively). In this paper we use the term 'landward' to encompass the Pilbara's terrestrial, aquatic and riparian environments, but not marine inter-tidal ecosystems such as mangroves. For clarity, the spectral characteristics of species comprising these two compositionally distinct communities have been considered separately, even though they share a number of species.

Figure 3a plots $F_{\text {peakc }}$ against $Q$ for reference search-mode calls by the 14 microbat species found in the Pilbara's landward environments (excluding mangroves). It shows that search-mode sequences by 13 of the 14 microbat species could be identified using a combination of $F_{\text {peak }}$ and $Q$, provided that departure call sub-sequences (sensu 'rising' and 'falling' sub-sequences in Bullen and McKenzie 2002a) were ignored in separating Nyctophilus bifax daedalus from N. g. geoffroyi sequences (Figure 4). The exception is Taphozous hilli which was too similar to be resolved from T. georgianus (except
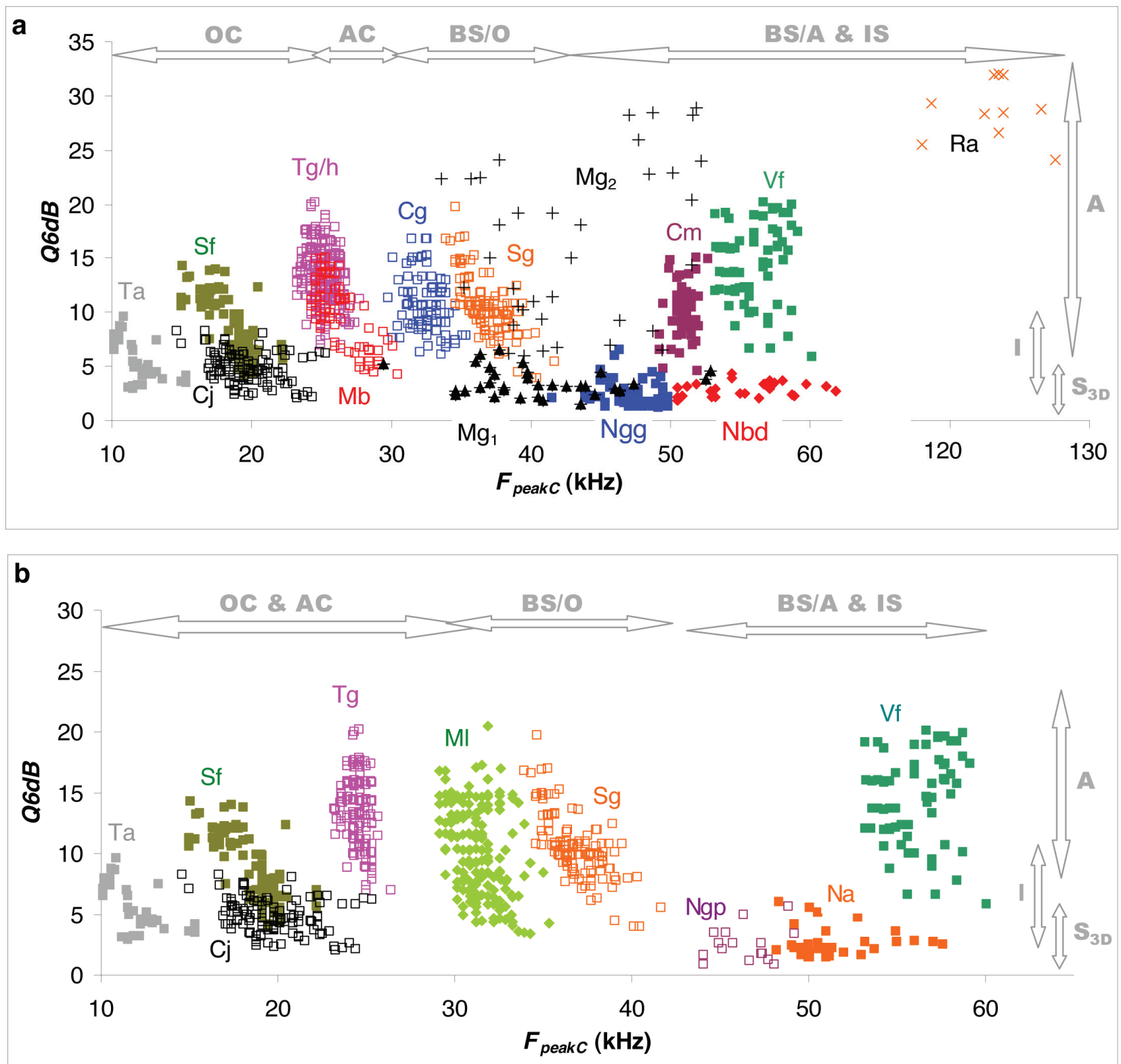

Figure 3 Scatterplot of $F_{\text {peak }}$ versus $Q$ of the strongest harmonic in reference search-mode echolocation calls by (a) the 14 species found in the Pilbara's landward environments, and (b) the 9 species found in the Pilbara's mangrove environments. Species codes comprise the first letter of the genus and species names (see Table 1). Sample sizes are provided in Tables 3 and 4. Microhabitat and foraging strategy categories from Tables 5 and 8 are superimposed. 


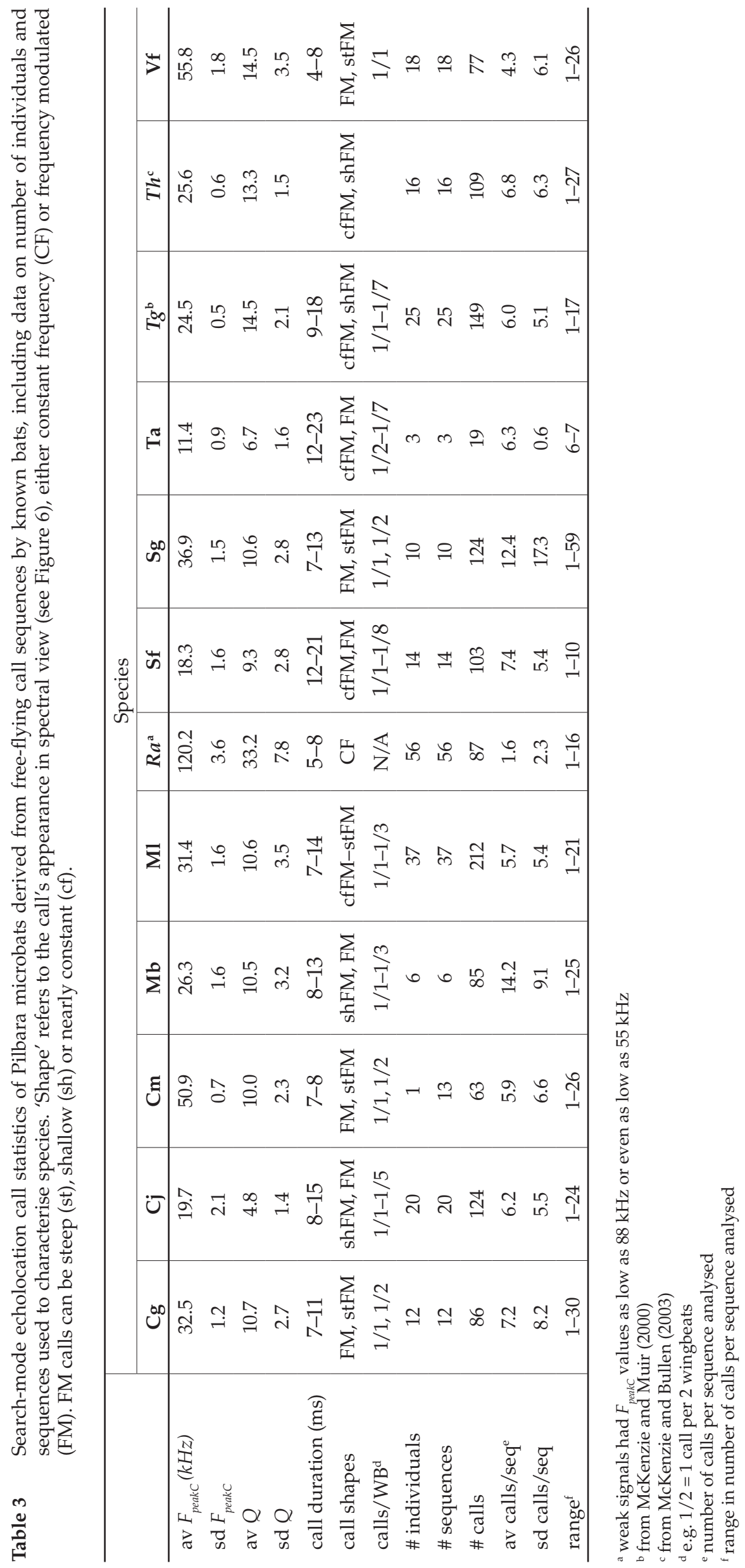




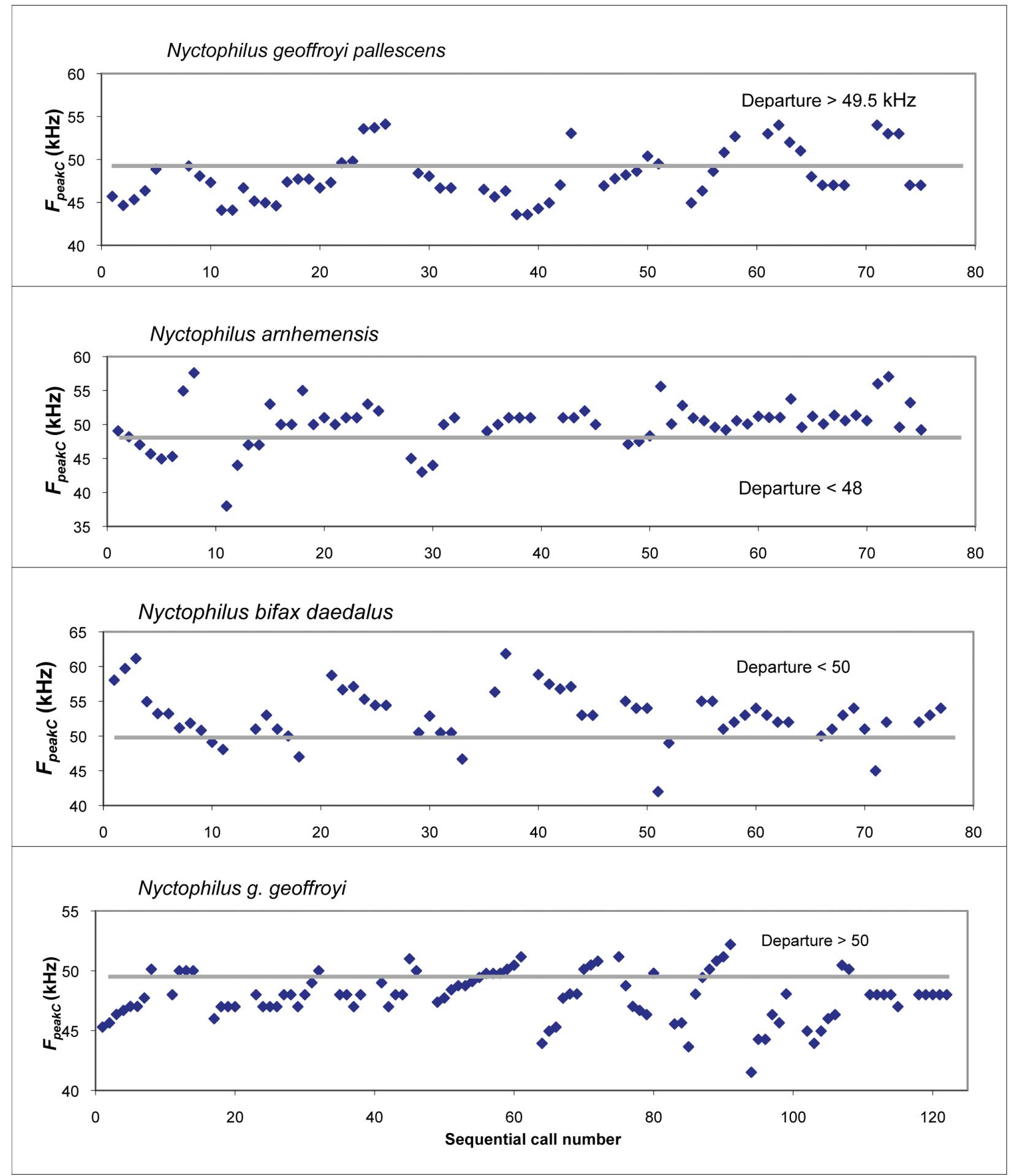

Figure 4 Search-mode sequence data for four Nyctophilus species. Individual bat sequences are separated by spaces. The grey horizontal lines represent the arbitrary boundary used to distinguish between the normal and the departure subsequences for species recognition. Individual dots represent the $F_{\text {peakc }}$ value of each call within a sequence. 
statistically; see McKenzie and Bullen 2003).

Macroderma gigas has a surface foraging strategy with two modes. It perches in vegetation to ambush passing prey (either on the ground or in the air), and it also gleans surfaces such as the ground while in-flight (e.g. Churchill 1998). Its echolocation calls showed wide variation in both $F_{\text {peakc }}$ and $Q$ values, but occupied the spectral spaces between, above and below Scotorepens greyi and Chalinolobus morio, with some overlap (Figure 3a). Unlike other microbats using the same frequency band, $M$. gigas calls were often prolonged (av. ca. $15 \mathrm{~ms}$, ranging up to 50 - see Figure 5), usually complex in terms of frequency when displayed in time domain (W-, M-, N-, or U-shaped FM, or stepped CF - see Figures $6 \mathrm{a}$ and $6 \mathrm{~b}$ ), and usually irregularly spaced call-to-call in sequences (examples are illustrated in Figure 6a, sequences 2 to 4 ). Where sequences were regular, the call repetition-rate corresponded to their relatively low wing-beat frequency $(6.96+/-$ $0.71 \mathrm{~Hz}$; Bullen and McKenzie 2002b), eliminating the possibility of confusion with approach-mode and intercept-mode calls of smaller microbats, with their much higher wing-beat frequencies, using the same spectral space. The call complexity distinguished them from the search-mode calls of all other species. Our reference calls were recorded in two separate contexts, and the sub-clustering recorded for $M$. gigas in Figure 5 suggests contextspecific use of these spectral spaces:

1. Recordings of flying M. gigas observed just after leaving a mine adit (Klondyke Queen, 2120'S,
11953’E) after dark: brief (<8 ms), low $Q(<6)$ calls with peak frequencies between 34 and 55 $\mathrm{kHz}$ (labelled ' $\mathrm{Mg}_{1}$ ' in Figure 3a, and plotted as solid triangles in Figure 5). Call complexity in combination with low $Q$ distinguishes $M$. gigas calls in this category from calls by all other microbats in the same frequency band and were used to identify unknown sequences (see Figure 6a sequences 1 to 6 , and the first 5 calls displayed in Figure 6b).

2. Recordings of $M$. gigas flying back and forth after attempting to to re-enter the mine entrance at Whim Creek (20 $\left.50^{\prime} \mathrm{S}, 117^{\circ} 49^{\prime} \mathrm{E}\right)$ past the observers: prolonged (10-50 ms), high $Q$ (6-36), CF and complex FM calls with peak frequencies between 33 and $53 \mathrm{kHz}$ (hollow squares in Figure 5). Call duration is sufficient for diagnosis. Call complexity in combination with 'call duration' distinguishes these calls from other species using the same band, and calls from these recordings were used as reference calls to identify unknown sequences.

The second category is labelled ' $\mathrm{Mg}_{2}$ ' in Figure 3a. In addition, $M$. gigas sequences often included characteristic sub-sequences of audible chittercalls (see Figure 6a), described by Churchill (1998) as 'audible twitter' (see below). Examples of the call complexity compared to other species that use the same frequency band are displayed in Figure 6 (Figure $6 \mathrm{~b}$ versus $6 \mathrm{~d}$ ). In the Pilbara, $M$. gigas also emits the loud audible 'chirping sounds' described by Kultzer et al. (1984).

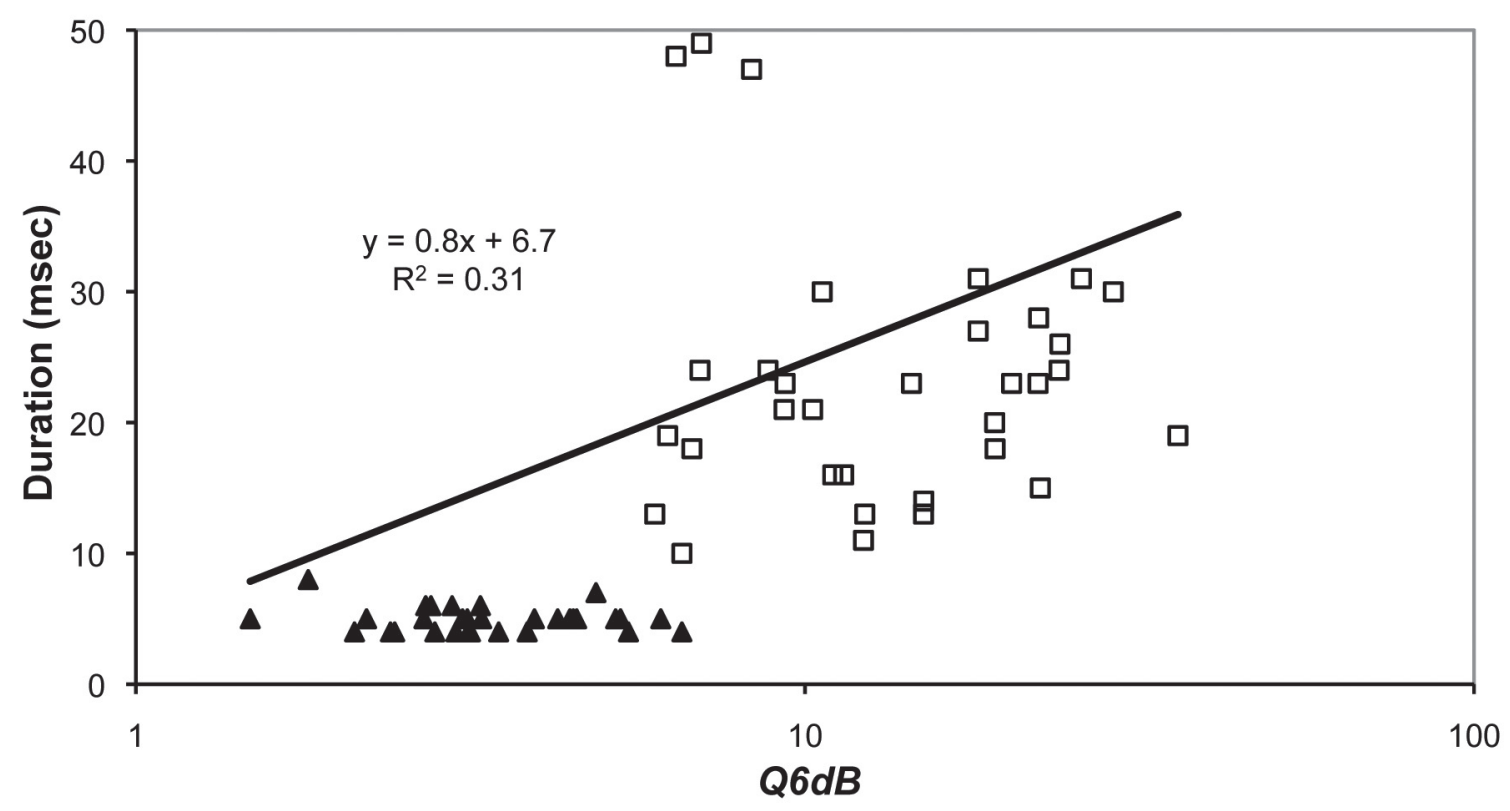

Figure 5 Scatterplot of $Q$ versus 'Duration' for the strongest harmonic of $M$. gigas calls recorded in two different contexts: in-flight soon after emerging from a roost (solid triangles), and attempting to re-enter a roost-adit past the observers (hollow squares). 

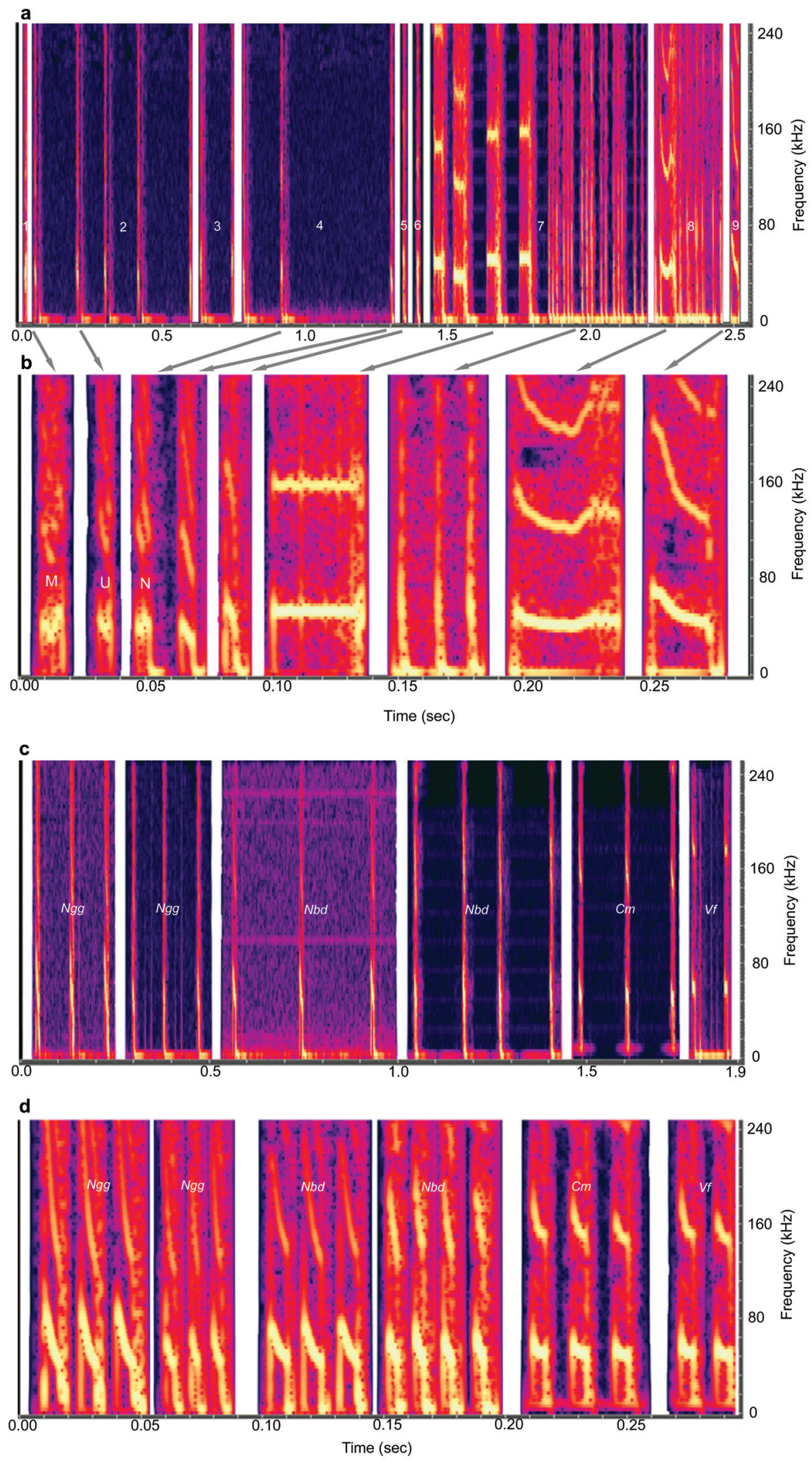

Figure 6 Search-mode call sequences in time domain by M. gigas and other Pilbara species that use the same frequency band. (a) Sections from nine in-flight sequences by M. gigas showing different call types and durations, and including sequences (labelled 2, 3 and 4) showing the characteristically irregular call-repetition rates. Chitter calls are also illustrated (the second half of sequences 7 and 8). (b) Close-up views of the variation seen in $M$. gigas calls, with spacing between calls removed. (c) Sections from typical sequences by Pilbara N. g. geoffroyi, N. bifax daedalus, C. morio and $V$. finlaysoni showing typically steady call repetition rates. (d) Close-up views of calls shown in (c) with the spacing between calls removed. 
Additional call attributes were also required to separate some of the nine species comprising the mangrove microbat community (Figure $3 b$ ):

- Departure sub-sequences (sensu Bullen and McKenzie 2002a) had to be ignored to separate $N$. arnhemensis from $N$. g. pallescens sequences (Figure 4).

- Two call characteristics were useful in resolving the spectral overlap between the mangrove specialist $M$. loriae and the common landward species Chalinolobus gouldii (Figures $3 \mathrm{a}$ and b), which ventured into the landward edge of mangroves occasionally (McKenzie and Start [1989] recorded 1 C. gouldii for every 20 M. loriae). $M$. loriae sequences often include calls with $Q$ values well below 5.1 (the lower limit for $C$. gouldii), and its calls had a narrower bandwidth $\left(\mathrm{F}_{\min }\right.$ to $\mathrm{F}_{\max }$ range and less curvilinear shape in time domain) for any given $\mathrm{F}_{\text {peakc }}$ value (Milne 2002).

\section{Organisation of echolocation calls in spectral space}

From an ecological perspective, the 'spectral' space between species in the Pilbara's landward community is almost entirely occupied below 60 $\mathrm{kHz}$ (Figure 3a). Except for T. georgianus and T. hilli in the eastern Pilbara, and for the occasional C. gouldii venturing into mangroves, species' normal, in-flight, search-mode calls show no more than partial overlap in both communities, and species are regularly arrayed to occupy the available spectral space. The reasons for the partial overlaps between $S$. flaviventris and $C$. jobensis, and between $M$. beccarii and T. georgianus/hilli calls, were explored in McKenzie and Bullen (2003).

The Pilbara's landward community also includes one hipposiderid, Rhinonicteris aurantia. Its distinctive echolocation calls are of constant frequency (rather than frequency modulated), and have a very high $Q$ and frequency $\left(F_{\text {peakc }}\right.$ between 112 and 128, averaging $120 \mathrm{kHz}$, Table 3). However, individual weak calls in these sequences sometimes returned low readings, between 55 and $110 \mathrm{kHz}$, that we treated as artefacts of the recording equipment representing inharmonic partials that

Table 4 Search-mode echolocation call statistics of Pilbara Nyctophilus spp. and M. gigas derived from free-flying call sequences by known bats (individuals observed outside roost sites, cyalume releases etc., see 'Methods'). Data on number of individuals and sequences used to characterise species are included. The three columns for M. gigas provide statistics for their constant frequency (CF), prolonged frequency modulated (FM) and brief FM calls, respectively. The first two columns may not be search-mode calls.

\begin{tabular}{|c|c|c|c|c|c|c|c|}
\hline & \multicolumn{7}{|l|}{ Species } \\
\hline & $\mathrm{Mg}$ & $\mathrm{Mg}$ & $\mathrm{Mg}$ & $\mathbf{N a}^{a}$ & $\mathbf{N b d}^{a}$ & $\mathrm{Ngg}^{a}$ & $\mathrm{Ng}^{a}$ \\
\hline av $F_{\text {peakc }}(\mathrm{kHz})$ & 46.3 & 42.4 & 40.5 & 51.3 & 53.8 & 47.3 & 47.5 \\
\hline $\operatorname{sd} F_{p e a k c}$ & 7.7 & 5.0 & 5.5 & 2.1 & 2.9 & 2.0 & 2.6 \\
\hline $\min$ & 35.7 & 33.6 & 29.0 & 48.2 & 50.5 & 41.5 & 43.6 \\
\hline $\max$ & 52.6 & 52.2 & 55.6 & 57.6 & 61.8 & 49.8 & 49.2 \\
\hline av Q & 26.3 & 13.0 & 3.5 & 2.5 & 2.9 & 2.3 & 2.4 \\
\hline sd Q & 6.8 & 6.0 & 1.2 & 1.0 & 0.6 & 1.3 & 1.6 \\
\hline av call duration (ms) & 26.8 & 22.9 & 4.9 & 5.6 & 5.0 & 5.4 & 5.1 \\
\hline sd call duration & 4.9 & 10.0 & 0.9 & 1.0 & 0.8 & 1.4 & 1.9 \\
\hline duration range $(\mathrm{ms})$ & $18-31$ & $11-50$ & $4-8$ & $3-7$ & $4-7$ & $3-7$ & $3-9$ \\
\hline call shapes & complex CF & complexFM & complex FM & ststFM & ststFM & ststFM & ststFM \\
\hline calls/WB & -- & -- & 4/1-1/1 & $1 / 1$ & $1 / 1,1 / 2$ & $1 / 1$ & $1 / 1$ \\
\hline av calls/seq ${ }^{\mathrm{b}}$ & 1.5 & 1.2 & 4.4 & 10.8 & 6.1 & 7.5 & 9.5 \\
\hline sd calls/seq & 1.0 & 0.5 & 3.1 & 9.3 & 2.5 & 3.2 & 8.7 \\
\hline range in calls/seq & $1-3$ & $1-3$ & $1-10$ & $4-28$ & $2-11$ & $4-14$ & $5-30$ \\
\hline \# individuals (N) & 4 & 24 & 10 & 6 & 10 & 14 & 8 \\
\hline \# sequences & 4 & 27 & 10 & 6 & 10 & 15 & 8 \\
\hline \# calls (n) & 6 & 31 & 44 & 65 & 59 & 91 & 63 \\
\hline Departure $F_{\text {peakc }}$ & -- & -- & -- & $48.0-38.0$ & $42.0-50.0$ & $50.0-52.2$ & $49.5-54.1$ \\
\hline
\end{tabular}

a includes data from Bullen and McKenzie (2002a)

${ }^{\mathrm{b}}$ number analysed 
Table 5 Foraging microhabitats of Pilbara microbats $(n=$ number of observations, $N=$ numbers of individuals). Microhabitat codes are explained in 'Methods'.

\begin{tabular}{|c|c|c|c|c|c|c|}
\hline \multirow{2}{*}{ Species } & \multicolumn{4}{|c|}{ Foraging microhabitats } & \multirow{2}{*}{$n$} & \multirow{2}{*}{$N$} \\
\hline & OC & AC & $\mathrm{BS} / \mathrm{O}$ & BS/A-IS & & \\
\hline $\operatorname{Tg}^{\mathrm{a}}$ & 59 & 2 & & & 61 & 61 \\
\hline $\mathrm{Ta}^{\mathrm{a}}$ & 34 & & 1 & & 35 & 34 \\
\hline Sf & 33 & 3 & & & 36 & 26 \\
\hline $\mathrm{Cj}^{\mathrm{a}}$ & 113 & 35 & 14 & & 162 & 153 \\
\hline $\mathrm{Mb}$ & 8 & 15 & 10 & & 33 & 19 \\
\hline $\mathrm{Ml}^{\mathrm{a}}$ & 21 & 66 & 59 & 46 & 192 & 159 \\
\hline $\mathrm{Cg}$ & 6 & 34 & 105 & 11 & 156 & 131 \\
\hline $\mathrm{Mg}$ & 1 & 4 & 21 & 6 & 32 & 32 \\
\hline $\mathrm{Sg}$ & & 13 & 133 & 28 & 174 & 121 \\
\hline$V f^{a}$ & & & 12 & 52 & 64 & 60 \\
\hline $\mathrm{Ra}$ & & & 9 & 79 & 88 & 34 \\
\hline $\mathrm{Cm}$ & & & 1 & 6 & 7 & 4 \\
\hline $\mathrm{Nbd}$ & & & 7 & 78 & 85 & 69 \\
\hline $\mathrm{Na}^{\mathrm{a}}$ & & & & 45 & 45 & 39 \\
\hline $\mathrm{Ngg}^{\mathrm{b}}$ & & & & 3 & 3 & 3 \\
\hline $\mathrm{Ngp}^{\mathrm{a}}$ & & & & 46 & 46 & 38 \\
\hline
\end{tabular}

a includes data from McKenzie and Start (1989)

${ }^{\mathrm{b}}$ consistent with Carnarvon Basin and Little Sandy Desert populations (McKenzie and Muir 2000; McKenzie et al. 2002)

were not integer multiples of the fundamental frequency (first harmonic).

\section{Species foraging niche}

Clear patterns in microhabitat-use emerged from the observational data (Table 5), which allowed species to be compared in terms of the airspace clutter they encountered in their usual foraging microhabitat. At the two extremes T. australis, $S$. flaviventris and T. georgianus/hilli hunted in open airspace well clear of obstructions, while the four Nyctophilus spp., C. morio, R. aurantia and Vespadelus finlaysoni hunted in cluttered airspace, close to surfaces. The remaining species hunted in various intermediate levels of clutter.

Six agility classes could be distinguished when we compared species in terms of their manoeuvres (Table 6, final column); four of these (classes 3 to 6) considered to be agile on the basis of their asymmetric turn capabilities. Of the species in agility class 3 , however, we noted that $N$. $b$. daedalus and $N$. arnhemensis performed their most energetic turns at relatively low flight speeds compared to $T$. georgianus and $M$. loriae, and that $M$. gigas sacrificed altitude during these turns. These observations suggest that $N . b$. daedalus, $N$. arnhemensis and $M$. gigas are less agile than T. georgianus and M. loriae. Further evidence for this difference was provided by our flight chamber observations that the Nyctophilus were the only species to hover (Table 6). Nyctophilus g. pallescens hovers lasted nearly three seconds, and some $N$. arnhemensis hovers lasted five to seven seconds. The uncertainty about S. flaviventris agility reflected the lack of flight chamber test data, but free-flight observations of social dog-fighting reported by Churchill (1998) and of it foraging between tree canopies in the Little Sandy Desert (McKenzie et al. 2002), indicate that it is capable of tight turns.

Two of the flight speeds reported in Table 7 are based on small sample sizes. The $N$. g. geoffroyi value of $4.7 \mathrm{~m} \mathrm{sec}^{-1}$ is based on only 8 readings from 6 individuals, while the value of $5.6 \mathrm{~m} \mathrm{sec}^{-1}$ for $C$. morio is based on 4 readings from 1 individual. These speed values are consistent with published data from southern Western Australia (Bullen and McKenzie 2001), that were based on 213 readings from 19 individual $N$. g. geoffroyi $\left(4.4 \mathrm{~m} \mathrm{sec}^{-1}\right)$, and 526 readings from 57 individual $C$. morio $(5.3 \mathrm{~m}$ $\left.\sec ^{-1}\right)$.

Taken together, the data on agility and flight speed are consistent with published foraging strategies from elsewhere and our field observations of foraging behaviours (Table 8). This includes observations on $19 N$. b. daedalus that were captured in mist nets set from late dusk onwards at canopy, 


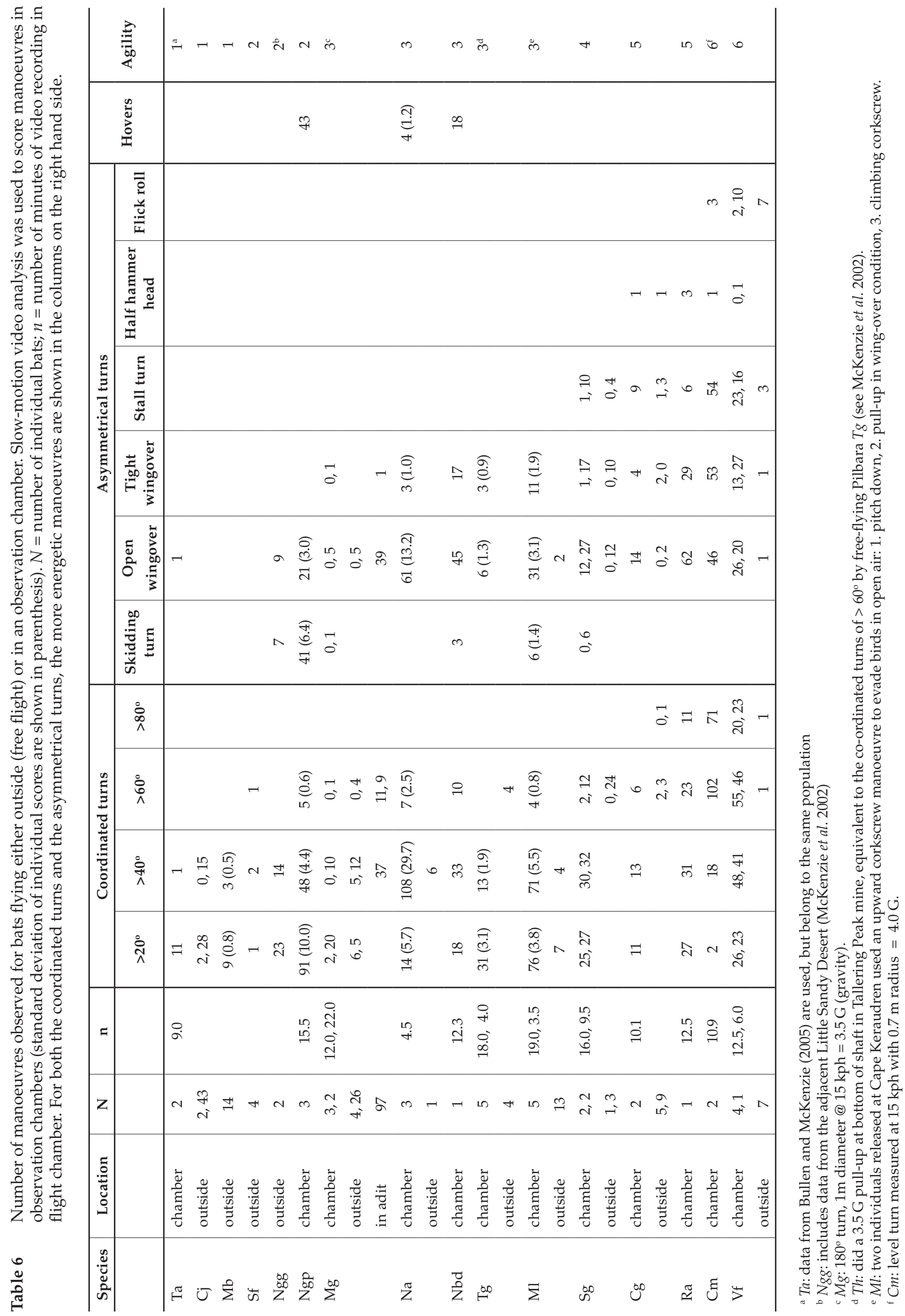


lower branch and shrub height at Weeli Wolli Spring (site RHNC48) in February 2006, and released with bioluminescent tags. After release, six were observed foraging among the upper branches and canopies of River Gum woodland, up to $20 \mathrm{~m}$ above the ground. They would perch for several minutes at a time, and/or spiral slowly around and through the canopy before commuting to the next canopy at higher flight speeds, behaviours consistent with ambushing and gleaning. Even moderately agile turns (Agility class 3 in Table 8) performed at high flight speeds $\left(>7.5 \mathrm{~m} \mathrm{sec}^{-1}\right)$ imply an air superiority strategy and are consistent with field observations of the relevant species outturning their prey. Species observed to intercept their prey during a straight, high speed pass had the lowest agility ratings and high flight speeds. Bat species with a 'surface' foraging strategy $\left(\mathrm{S}_{\mathrm{a}^{\prime}}, \mathrm{S}_{\mathrm{H}}\right.$ or $\mathrm{S}_{3 \mathrm{D}}$ in Table 8) all showed moderate to low agility in conjunction with low flight speeds. Exceptions were the large predator (M. gigas), which has the highest wing loading of all the surface strategists (13.5 versus $4.7-5.5 \mathrm{~N} \mathrm{~m}^{-2}$ ) and consequently needs proportionally higher flight speed to generate sufficient lift even for level flight, and M. loriae, which has a dual-mode airframe (Bullen and McKenzie 2002b, 2004, 2007). This mode-change was observed during fieldwork at Cape Keraudren in November 2007, when four M. loriae individuals foraging close above the mangrove canopy at a mode flight speed of $7.8 \mathrm{~m} \mathrm{sec}^{-1}$ were seen to gain altitude, then depart at measured velocities exceeding $11 \mathrm{~m} \mathrm{sec}^{-1}$. Equivalent instances of very fast flight by this species were noted during a previous visit in February 2006.

\section{Echolocation survey}

Figure 7 overlays reference calls (as solid squares) with unknown calls (as hollow squares) recorded at landward sites in the Pilbara. Unknown calls that plotted on the periphery of a reference call cluster were identified only if they were in continuous sequence with calls that fell within the cluster. Sequences of Saccolaimus flaviventris and Taphozous spp. sometimes included one or two second harmonic calls that were in the same frequency band as C. gouldii and N. geoffroyii calls, respectively, but with distinctively flat $\mathrm{CF}$ shapes in time domain and high $Q$ values. Examples for S. flaviventris are plotted in Figure 7. On the basis that we have never recorded a reference call of $S$. flaviventris in the 8 or the $24 \mathrm{kHz}$ range, or heard an $8 \mathrm{kHz}$ echolocation sequence in Western Australia, we conclude that the frequency of its fundamental harmonic is about $16 \mathrm{kHz}$ (range 15 to 19 ).

Almost all sequences and most of the individual search-mode calls that we recorded were identifiable unless the recording was visibly distorted by atmospheric attenuation, echoes or over-saturation. Only Taphozous sequences remain unresolved, so they are listed as T. georgianushilli (Tgh) in the site compositional analysis below. With the same restrictions, the equivalent result was obtained for bats belonging to the mangrove community; unknown sequences could be identified unambiguously although, in this case, the site species lists were based on captures rather than call identification, and were published in McKenzie and Start (1989). On the basis that all clear sequences by 16 of the region's 17 microbat species were identified, we concluded that spectral parameters provided a viable survey tool.

ICE and Chao2 procedures in EstimateS both produced an estimate of 13 species from the 64

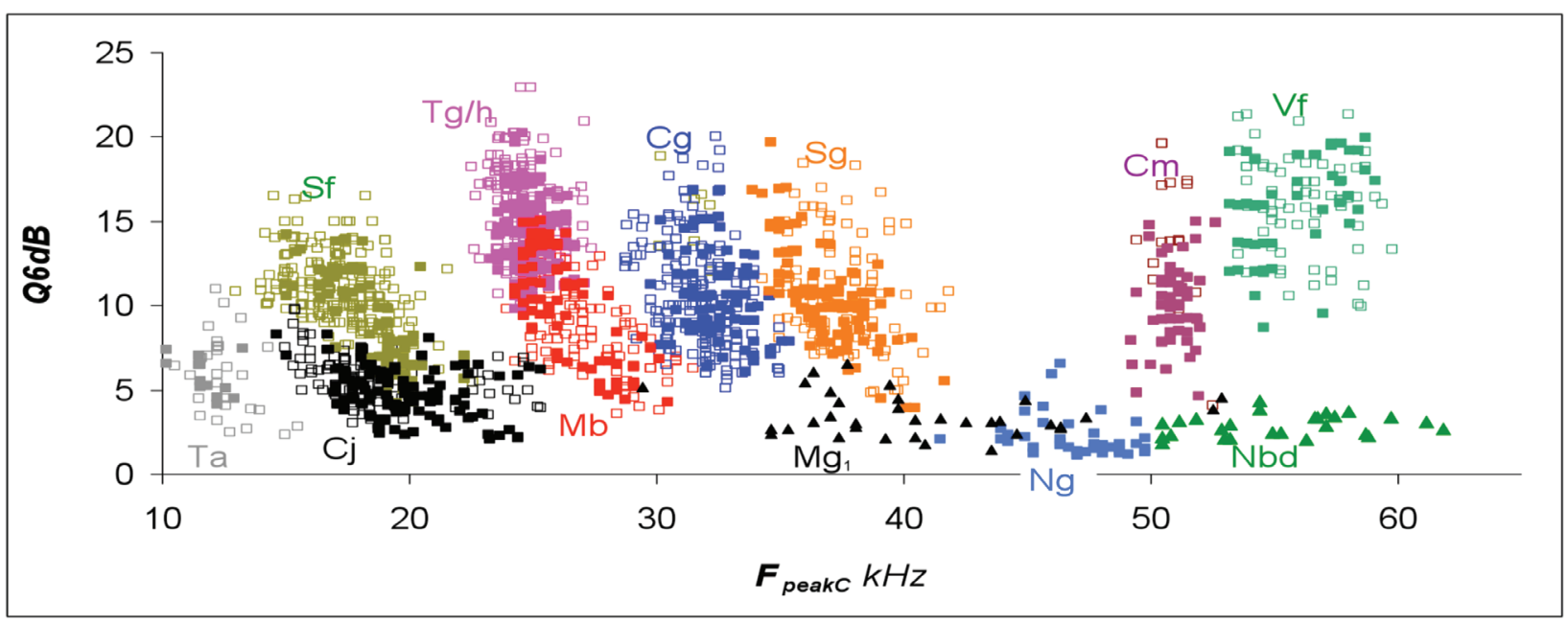

Figure 7 Scatterplot of strongest harmonic $F_{\text {peak }}$ versus $Q$ of 'unknown' search-mode echolocation calls (hollow squares) overlaid onto reference calls (solid squares), for identification purposes. 
Table 7 Mode flight speed of Pilbara bats measured in the field ( $N=$ number of individual bats; $n=$ total number of speed measures). Species codes as in Table 1.

\begin{tabular}{|c|c|c|c|c|c|}
\hline Species & Flight speed $\left(\mathrm{m} \mathrm{s}^{-1}\right)$ & $\mathbf{N}$ & $\mathrm{n}$ & av $n / N$ & $\operatorname{sd} n / N$ \\
\hline $\mathrm{Cj}$ & 8.6 & 101 & 307 & 3.1 & 3.0 \\
\hline $\mathrm{Cg}$ & 6.9 & 122 & 243 & 2.0 & 2.6 \\
\hline $\mathrm{Cm}$ & $5.6^{a}$ & 1 & 4 & & \\
\hline $\mathrm{Mb}$ & 7.8 & 14 & 69 & 4.9 & 6.6 \\
\hline $\mathrm{Mg}$ & 6.9 & 106 & 283 & 2.5 & 1.5 \\
\hline Ml & 7.8 & 16 & 140 & 5.4 & 4.5 \\
\hline $\mathrm{Na}$ & 5.3 & 6 & 40 & 5.0 & 3.7 \\
\hline $\mathrm{Nbd}$ & 5.6 & 28 & 182 & 6.3 & 3.4 \\
\hline$N g g^{\mathrm{b}}$ & 4.7 & 6 & 8 & 1.3 & 0.5 \\
\hline Ngp & 5.0 & 14 & 75 & 5.0 & 3.4 \\
\hline $\mathrm{Ra}$ & 6.1 & 79 & 119 & 1.5 & 0.7 \\
\hline Sf & 8.1 & 13 & 29 & 2.2 & 1.4 \\
\hline $\mathrm{Sg}$ & 6.1 & 120 & 398 & 3.3 & 3.9 \\
\hline $\mathrm{Ta}$ & $8.6^{c}$ & $>30$ & 461 & $<10$ & \\
\hline $\operatorname{Tg} \mathcal{E} T h^{\mathrm{d}}$ & 8.1 & 76 & 191 & 2.4 & 1.6 \\
\hline Vf & 5.6 & 53 & 85 & 1.6 & 1.0 \\
\hline
\end{tabular}

${ }^{a}$ mode flight speed for Coolgardie population $=5.3 \mathrm{~m} \mathrm{sec}^{-1}(N=57, n=256)$ (Bullen and McKenzie 2001)

${ }^{\mathrm{b}}$ data from adjacent Little Sandy Desert population (McKenzie and Bullen 2003)

c adjusted from Bullen and McKenzie (2001) because hand-launch measurements of molossids under-rate $V_{\text {mode }}$ by $10 \%$

d unable to distinguish $T g$ from $T h$ echolocation calls

Table 8 Foraging Strategy (from Bullen and McKenzie 2004): interceptor (I), air-superiority (A), ambusher surface and level air-to-surface $\left(\mathrm{S}_{\mathrm{a}} \& \mathrm{~S}_{\mathrm{H}}\right)$, and $3 \mathrm{D}$ air-to-surface $\left(\mathrm{S}_{3 \mathrm{D}}\right)$.

\begin{tabular}{l|c|c|c}
\hline Species & Agility (from Table 6) & Flight speed (from Table 7) & $\begin{array}{c}\text { Published data and field } \\
\text { observations }\end{array}$ \\
\hline $\mathrm{Mb}$ & 1 & 7.8 & $\mathrm{I}^{\mathrm{a}}$ \\
$\mathrm{Cj}$ & 1 & 8.6 & $\mathrm{I}^{\mathrm{a}}$ \\
$\mathrm{Ta}$ & 1 & 8.6 & $\mathrm{I}^{\mathrm{abc}}$ \\
$\mathrm{Ngg}$ & 2 & 4.7 & $\mathrm{~S}_{3 \mathrm{D}}^{\mathrm{abc}}$ \\
$\mathrm{Ngp}$ & 3 & 5.0 & $\mathrm{~S}_{3 \mathrm{D}} \mathrm{de}^{\mathrm{f}}$ \\
$\mathrm{Na}$ & 3 & 5.3 & $\mathrm{~S}_{3 \mathrm{D}}$ \\
$\mathrm{Nbd}$ & 3 & 5.6 & $\mathrm{~S}_{3 \mathrm{D}^{\mathrm{e}}}$ \\
$\mathrm{Mg}$ & 3 & 6.9 & $\mathrm{~S}_{\mathrm{H}^{\prime}} \mathrm{S}^{\mathrm{ag}}$ \\
$\mathrm{Ml}$ & 2 & 7.8 & $\mathrm{I}^{\mathrm{a}^{\mathrm{a}}}$ \\
$\mathrm{Sf}$ & 3 & 8.1 & $\mathrm{~A}^{\mathrm{ac}}$ \\
$\mathrm{Tg}$ & 3 & 8.1 & $\mathrm{~A}^{\mathrm{a}}$ \\
$\mathrm{Th}$ & 4 & 8.1 & $\mathrm{~A}^{\mathrm{a}}$ \\
$\mathrm{Sg}$ & 5 & 6.1 & $\mathrm{~A}^{\mathrm{a}}$ \\
$\mathrm{Ra}$ & 5 & 6.1 & $\mathrm{~A}^{\mathrm{be}}$ \\
$\mathrm{Cg}$ & 6 & 6.9 & $\mathrm{~A}^{\mathrm{abe}}$ \\
$\mathrm{Cm}$ & 6 & 5.6 & $\mathrm{~A}^{\mathrm{b}}$ \\
$\mathrm{Vf}$ & 5.6 & $\mathrm{~A}^{\mathrm{ac}}$ \\
\hline
\end{tabular}

${ }^{a}$ McKenzie et al. (2002); ${ }^{b}$ Bullen and McKenzie (2001); 'Churchill (1998); ${ }^{\mathrm{d}}$ McKenzie and Start (1989); ${ }^{\mathrm{e}}$ Authors' empirical observations of field behaviour, including information on N. b. daedalus in Results; ${ }^{\mathrm{f}}$ McKenzie and Churchill (2008); ${ }^{\circ}$ Richards et al. (2008). 
Table 9 Sub-region and survey area faunas (excluding mangrove sites), incorporating literature and WA Museum records.

\begin{tabular}{|c|c|c|c|c|c|c|c|c|c|c|c|c|c|c|c|}
\hline $\begin{array}{l}\text { Survey area } \\
\text { (Figure 1) }\end{array}$ & $\mathrm{Cg}$ & $\mathrm{Cj}$ & $\mathrm{Cm}$ & $\mathrm{Mb}$ & Mg & Nbd & $\mathrm{Ng}$ & Ra & Sf & Sg & Ta & $\operatorname{Tg}$ & Th & Vf & $\begin{array}{l}\text { Distance to } \\
\text { coast }(\mathrm{km})\end{array}$ \\
\hline BDRS & 1 & 1 & & 1 & 1 & & 1 & 1 & 1 & 1 & 1 & 1 & & 1 & 390 \\
\hline BDRN & 1 & 1 & & 1 & 1 & & 1 & 1 & 1 & 1 & & 1 & & 1 & 330 \\
\hline RHNC & 1 & 1 & 1 & 1 & 1 & 1 & 1 & 1 & 1 & 1 & 1 & 1 & 1 & 1 & 310 \\
\hline RHNE & 1 & 1 & & 1 & & 1 & 1 & 1 & 1 & 1 & 1 & & & 1 & 250 \\
\hline ТСМВС & 1 & 1 & & 1 & 1 & & 1 & 1 & 1 & 1 & & 1 & 1 & 1 & 230 \\
\hline RHNW & 1 & 1 & & 1 & 1 & & 1 & & 1 & 1 & & 1 & & 1 & 210 \\
\hline TCMBE & 1 & 1 & & 1 & 1 & 1 & 1 & 1 & 1 & 1 & 1 & 1 & 1 & 1 & 210 \\
\hline TCMBW & 1 & 1 & & 1 & 1 & & 1 & & 1 & 1 & 1 & 1 & 1 & 1 & 200 \\
\hline NE & 1 & 1 & & 1 & 1 & & 1 & & 1 & 1 & 1 & 1 & 1 & 1 & 180 \\
\hline NW & 1 & 1 & & 1 & 1 & & 1 & 1 & 1 & 1 & 1 & 1 & & 1 & 180 \\
\hline WYE & 1 & 1 & & 1 & 1 & & 1 & 1 & 1 & 1 & & & & 1 & 150 \\
\hline MBE & 1 & 1 & & 1 & 1 & & & 1 & 1 & 1 & 1 & 1 & & 1 & 130 \\
\hline PE & 1 & 1 & & 1 & 1 & & 1 & & 1 & 1 & 1 & 1 & 1 & 1 & 130 \\
\hline PHYC & 1 & 1 & & 1 & 1 & & 1 & 1 & 1 & 1 & 1 & 1 & 1 & 1 & 100 \\
\hline PHYE & 1 & 1 & & 1 & 1 & & 1 & 1 & 1 & 1 & 1 & 1 & 1 & 1 & 100 \\
\hline MBW & 1 & 1 & & 1 & 1 & & 1 & 1 & 1 & 1 & 1 & 1 & & 1 & 90 \\
\hline OYE & 1 & 1 & & 1 & & & 1 & 1 & 1 & 1 & 1 & 1 & & 1 & 80 \\
\hline PW & 1 & 1 & & 1 & 1 & 1 & 1 & & 1 & 1 & 1 & 1 & & 1 & 80 \\
\hline WYW & 1 & 1 & & 1 & 1 & & 1 & & 1 & 1 & & 1 & & 1 & 80 \\
\hline OYW & 1 & 1 & & 1 & 1 & 1 & 1 & 1 & 1 & 1 & 1 & 1 & & 1 & 40 \\
\hline DRC & 1 & 1 & & 1 & 1 & 1 & 1 & 1 & 1 & 1 & 1 & 1 & & 1 & 20 \\
\hline DRE & 1 & 1 & & 1 & 1 & & 1 & & 1 & 1 & 1 & 1 & & 1 & 20 \\
\hline PHYW & 1 & 1 & & 1 & & & 1 & 1 & 1 & 1 & 1 & 1 & & 1 & 20 \\
\hline DRW & 1 & 1 & & 1 & 1 & 1 & 1 & 1 & 1 & 1 & & & & 1 & 10 \\
\hline \# survey areas & 24 & 24 & 1 & 24 & 21 & 7 & 23 & 17 & 24 & 24 & 19 & 21 & 8 & 24 & \\
\hline \# sub-regions & 4 & 4 & $1^{\mathrm{a}}$ & 4 & 4 & $3^{b}$ & 4 & $3^{c}$ & 4 & 4 & 4 & 4 & $2^{\mathrm{d}}$ & 4 & \\
\hline
\end{tabular}

a only in Hamersley RHNC

${ }^{\mathrm{b}}$ not from Chichester

${ }^{c}$ not from Fortescue

d not from Roebourne or Fortescue

sites sampled in landward environments. These indicated that no further species would be added after the $14^{\text {th }}$ (ICE) and $19^{\text {th }}$ (Chao2) sites were sampled. The field survey result was $100 \%$ of the estimation (of 13 species), bearing in mind that the region's two Taphozous species were not discriminated by the sampling method used. Nine species were estimated (Chao2 as well as ICE) for the 5 mangrove sites sampled, with no further species predicted to be added after the $3^{\text {rd }}$ site was sampled. Again, the field sampling result was 100\% of the estimated richness. Both the terrestrial and the mangrove community accumulation curves were asymptotic.

\section{Species distributions and conservation status in the Pilbara}

Table 9 combines the landward site lists according to survey areas, which allows available Museum and literature records to be added to the echolocation survey results, and T. georgianus to be separated from $T$. hilli. It shows that five species belonging to the landward community are more widespread than previously supposed, or are localised or have consistent gaps in their regional distributions, and that a sixth is ubiquitous but seasonal (Table 10). In combination, these two tables reveal that:

1. Taphozous hilli is not known from the 
Roebourne and Fortescue sub-regions, and has been found only in inland areas of the Hamersley and Chichester sub-regions that are in the 'desert bioclimatic zone', more than 100 $\mathrm{km}$ from the coast (Figure 1).

2. Under Western Australia's Wildlife Conservation Act (1950), the Pilbara population of Rhinonicteris aurantia is listed as rare and likely to become extinct and, under Australia's Environmental Protection and Biodiversity Conservation Act (1999), it is listed as vulnerable. Our results indicate that it is more common than previously recognised (Hall et al. 1997; Armstrong 2001), occurring in 17 of the 24 Pilbara survey areas. In 12 of these, the records are based on recordings made in the dry season, and in some cases in survey areas with no known roosts, suggesting that additional roost colonies remain to be discovered. We detected its calls at new sites in 10 of the 24 survey areas, despite $R$. aurantia's low detectability (bat detector range is $<3 \mathrm{~m}$ for this species) and the sparsity of our sampling (total of $<10$ hours recording across 3 sites per survey area). There are no records from the Fortescue, the only sub-region in which suitable cave roosts are scarce or absent.

3. The Pilbara population of Macroderma gigas is listed as vulnerable in the IUCN Red List (2002), and as priority 4 (in need of monitoring) by the Department of Environment and Conservation, Western Australia. Our results suggest that it is more common than previously supposed, occurring in 21 of the 24 survey areas, and in all 4 sub-regions. Its calls were detected at new sites in 10 of the 24 survey areas despite the sparsity of the sampling and the low intensity of M. gigas calls (bat detector range is $<3 \mathrm{~m}$ for M. gigas).

4. Nyctophilus $b$. daedalus is known from 3 of the region's 4 sub-regions (not from the Chichester), but only 7 of the 24 survey areas. Its apparent rarity may be an artefact of detectability assumptions ' 6 ' and ' 9 ' in Gannon et al. (2003, p. 48), and it is probably more widespread in these situations than the available data indicate. Pilbara bat species are not randomly distributed in 3-dimensional space and their calls do not have equal probability of detection (Gannon et al.'s assumptions ' 6 ' and ' 9 ', respectively) because they have different frequencies and intensities, so they were not equally detectable from ground-level. We observed $N$. $b$. daedalus foraging among the branches of the River Gum and paperbark trees, $15-25 \mathrm{~m}$ high, that form these riparian forests (Table 8). The problem was that its low intensity calls are detectable only to distances of 3-4 m, but our detectors were placed on the ground because recordings made nearer to the tree canopy were almost always swamped by insect calls, mainly bushcrickets.

5. In the Pilbara, C. morio is known only from the Weeli Wolli-Marillana Creek system in the RHNC survey area of the Hamersley subregion. Despite our focus on sampling riparian environments, we did not detect this species at any other site in the Pilbara. In contrast to $N$. b. daedalus, search-mode calls by C. morio that were released carrying bioluminescent tags were detectable to distances of at least $15 \mathrm{~m}$, so our echolocation records should have detected C. morio at the other Pilbara sites sampled, if it was present. Elsewhere in Australia, this species is characterised by having isolated extra-limital populations to the north of its otherwise temperate distribution (Young et al. 2008). Also, over the last four years, one of the authors (RB) has identified bat calls from ultrasound recordings from more than 200 sites scattered across the Gascoyne and Murchison bioregions, immediately south of the Pilbara. Taken together, these observations suggest that this extra-limital Pilbara population is indeed geographically localised.

6. Although nearly all previous records of $T$. australis from the Pilbara came from its coastal areas, additional records collected during this survey provide evidence for its presence throughout the region in winter (Tables 10 and 11). Even in winter, it was not recorded everywhere, partly because of the limited mid-winter sampling (see Appendix 1), but recordings from landward environments were uncommon compared even to species with less powerful calls. Elsewhere, this species can be detected within $2 \mathrm{~h}$ of dusk on most nights (Bullen and McKenzie 2005). There was only one summer record from the Pilbara - a call sequence recorded at Weeli Wolli Spring in February 2006.

\section{Assemblage composition}

The environmental attributes of the 69 recording sites (Figure 1) are listed in Appendix 1. When species were classified according to their cooccurrences at the 69 sites, the dendrogram's partition structure could be interpreted to the 4-group level (Figure 8) in terms of known habitat associations and roost preferences of their component species across their wider distribution in Australia. At this level, an ANOSIM test showed that association distances between species in different partitions were significantly greater than the distances between species in the same partition $($ real-F $=4.2$, best-F $=2.0, \%$ randomised $>$ real $=0$ ): 


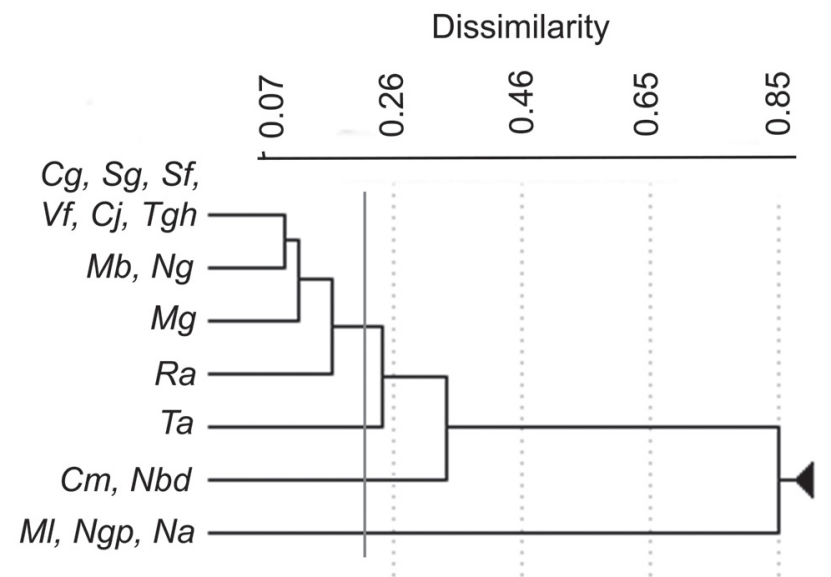

Figure 8 Species classified into four groups (grey line) according to their co-occurrences at the same sites. Dendrogram partition structure to the seven-group level is shown.

1. Ten species that are widespread in the region, some of which also occur in mangroves. This group includes species that prefer to roost in or on trees (N. g. geoffroyi, C. gouldii, S. greyi, S. flaviventris, $M$. beccarii and $C$. jobensis), as well as species that roost in caves and/or crevices (T. georgianus/hilli, V. finlaysoni, M. gigas and $R$. aurantia) and consequently have higher occupancy of sites in ranges (rugged outcrop country with rock crevices, slots, caves and often underground mine workings).

2. One tree-roosting molossid of the Australian temperate zone ( $T$. australis), that expands its geographic range in winter to include northern arid areas of the continent, including the Pilbara region (Bullen and McKenzie 2005).

3. Two specialists of productive riparian environments. $N$. $b$. daedalus normally forages in the canopy and upper branches of riparian forest. In contrast, despite having a detectability range $>15 \mathrm{~m}, \mathrm{C}$. morio was detected only from the Weeli Wolli-Marillana Creek complex of the RHNC survey area, which is consistent with available Museum records.

4. The three mangrove specialists (M. loriae, $N$. arnhemensis and N. geoffroyi pallescens) all have mesic tropical distributions elsewhere in Australia where they occur in rainforest, monsoon forest, riparian zones and mangrove communities (McKenzie and Rolfe 1986; van Dyck 2008).

The presence and absence matrix (69 site $x$ 16 species) from the echolocation survey was re-ordered according to the site and species classification analyses (Figure 9). Two communities were revealed, with up to 12 species in landward assemblages and up to 9 in the mangrove assemblages. Differences between the four sitedendrogram groups (Figure 10) could be explained using three environmental attributes: riparian development, distance to ranges and distance to coast (see Figure 11):

1. This group comprised landward sites more than $3 \mathrm{~km}$ from ranges (see Figure 11a). Obligate cave dwellers were rare or absent (T. georgianus/hilli, V. finlaysoni, M. gigas and $R$. aurantia). In this cluster, well-developed riparian sites with permanent or semipermanent pools were richer ( $>4$ species/ site) than dry sites with open low vegetation. M. beccarii, C. jobensis, S. flaviventris and N. g. geoffroyi favoured the sites with well-developed riparian zones.

2. Landward sites in or close to ranges that were also in well-developed riparian zones characterised by permanent pools and, at sites with the highest species richness ( $>8$ species), by tall paperbark forests with areas of bulrush swamp. These were the most specious sites; highest site occupancy for the obligate cave dwellers (T. georgianus/hilli, V. finlaysoni, M. gigas and $R$. aurantia) as well as large tree-roosting microbats such as S. flaviventris, C. jobensis, M. beccarii and N. g. georgianus, and the two riparian specialists (C. morio and N. b. daedalus), were recorded in this group.

3. Landward sites that were as close to ranges as the sites in Group 2, but were on smaller, less permanent watercourses and/or had more open riparian vegetation (see Figure 11b). The relatively poor riparian zone at most of these sites was reflected in the scarcity of M. beccarii, C. jobensis, S. flaviventris and N. g. geoffroyi.

4. The five mangrove sites formed a group because of three species, the mangrove specialists $N$. geoffroyi pallescens, $N$. arnhemensis and M. loriae. These species were unique to, and ubiquitous in, the mangrove sites sampled (see Figure 11c), and each of these species has its allopatric con-generic counterpart in the region's landward environments. For consistency, occasional mangrove records of the common landward species C. gouldii have been retained for this analysis, even though they were encountered on only three occasions, all on the landward edge of the mangroves.

Nestedness in species composition (Atmar and Patterson 1993, 1995) is overt in the landward sitegroups $[T=18.4, P<0.001$ for group- $1 ; T=20.4$, $P<0.001$ for Groups $2+3$ combined), with nearly all community members present at the bestdeveloped riparian sites, closest to ranges (Figure 
12). This plot of species richness versus 'caves' (an alternative measure of distance to ranges) and 'riparian development' summarises the importance of rugged landscapes and riparian zone quality as influences on assemblage richness in the landward microbat community.

No significant relationship was detected when we plotted the similarity in site species composition (Czekanowski) against Euclidean distance apart $(\mathrm{km})$ for all pairs of landward sites (Kendall Tau $=$ $0.02, P>0.05)$. Consequently, spatial autocorrelation was not treated as a factor liable to influence species composition.

\section{DISCUSSION}

\section{Spectral characters as a survey tool}

We could identify 16 of the 17 microbat species known in the Pilbara from their search-mode echolocation call sequences, a useful survey technique. The only constraint was the broad overlap in spectral characters observed between T. georgianus and its arid zone counterpart, T. hilli, in the landward community (Figure 3). Taphozous georgianus occurs throughout the region throughout the year (including its mangrove communities), while all 48 records (museum specimens) of T. hilli from the Pilbara are restricted to the region's 'desert bioclimate zone', more than $100 \mathrm{~km}$ inland (Figure 1, Table 9). Both species have large allopatric ranges elsewhere in northern Australia, and the reason for sympatry between two such morphologically and spectrally similar congenerics in the eastern Pilbara is unknown. It might reflect the seasonal heterogeneity in atmospheric conditions.

The two mangrove-dwelling Nyctophilus ( $N$. arnhemensis and N. g. pallescens) have calls with spectral characteristics similar to their allopatric landward counterparts ( $N$. bifax daedalus and $N$. g. geoffroyi, respectively), so the survey data on the mangrove pair were based only on capture records, and we recommend that future ultrasound recordings made in mangroves be identified using Figure 3b. Also, particular care has to be taken with the spectral identification of the mangrove specialist $M$. loriae because the common landward species $C$. gouldii occasionally ventures into the landward edge of the mangroves and has very similar search mode calls. We do not consider $C$. gouldii to be a member of the mangrove community, and have excluded it from the spectral plot (Figure $3 b)$.

Despite small sample sizes $(\mathrm{N}<10)$, the call frequencies listed in Tables 3 and 4 for T. australis, $M$. beccarii, $N$. arnhemensis and $C$. morio were consistent with previously published data from other regions (e.g. McKenzie and Bullen 2003).

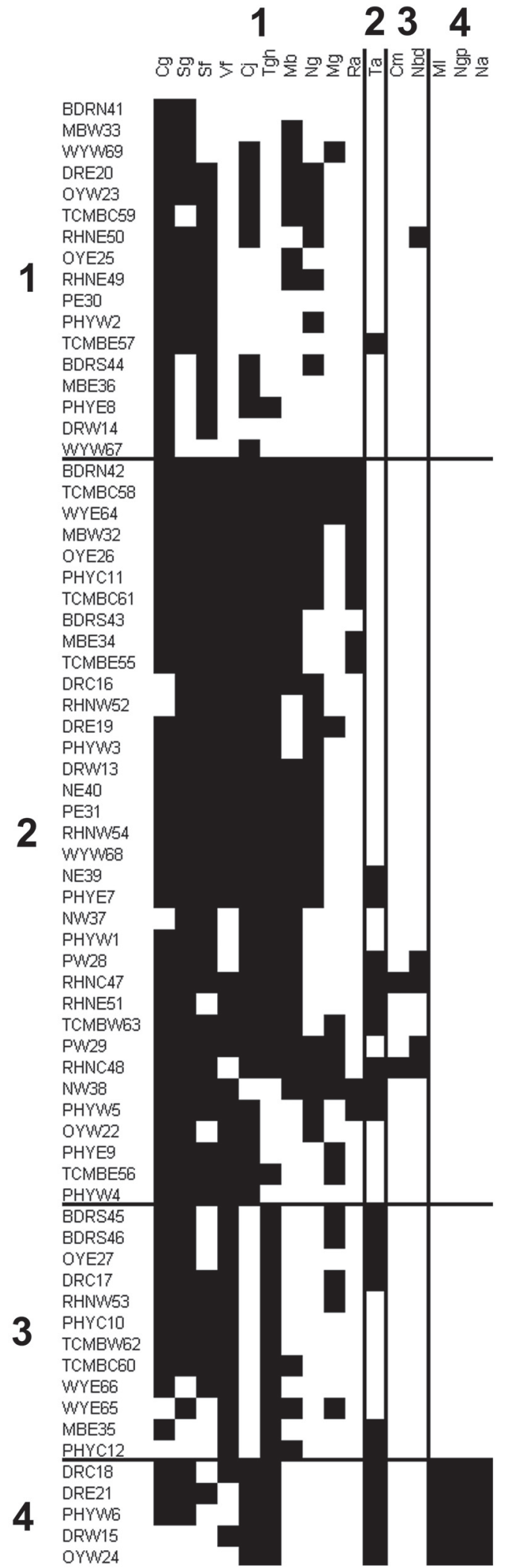

Figure 9 Microbat data matrix, with sites re-ordered according to similarities in their species composition, and the species re-ordered according to their co-occurrences at the same sites. Lines indicate classification partition boundaries at the four-group level (Figures 8 and 10). Site locations by survey area are shown in Figure 1. 
In particular, the values for $C$. morio were based on multiple passes by a single cyalume-tagged individual to minimise our interference with the Pilbara's isolated and apparently very localised population. Nevertheless, small sample sizes can cause problems in species recognition. In the Pilbara, N. g. geoffroyi typically emits sequences of search-mode calls with frequencies ranging from $42-50 \mathrm{kHz}$ (average 47.3, with departures to 52), rather than the $47-48 \mathrm{kHz}$ range that we reported earlier using a total of 38 calls (a single sequence from each of 8 individuals, Bullen and McKenzie 2002a). Similarly, in the Pilbara, N. g. pallescens calls range from $44-49 \mathrm{kHz}$ (average $=47.5$, with departures to 54.1, Figure 4) rather than 47-53 (50.7, with no departures) that we reported earlier based on 14 calls (single sequences by 3 individuals).

We noted earlier that recordings of $S$. flaviventris and Taphozous spp. sometimes included calls in the second harmonic, as has been noted for emballonurids from elsewhere (e.g. Obrist et al. 1993). Most of these were calls interspersed among first harmonic calls in sequences, but occasional calls were found that switched between the first and second harmonic in the middle of a call. In neither case were other species of echolocating bats present.

\section{Call spectral characteristics and foraging niche}

Differences in call structure are thought to contribute to resource partitioning by sympatric species through niche differentiation (Heller and Helversen 1989; Neuweiler 1990). Foraging niche categories have been superimposed on Figure 3. Clearly, these 'spectral' plots can be treated as representations of resource allocation because the species' call parameters showed clear, functionally appropriate relationships with foraging niche: call frequency with foraging microhabitat, and the

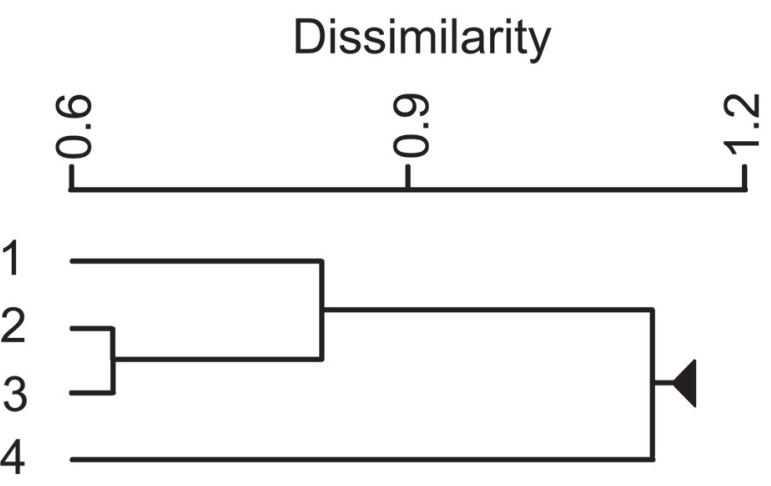

Figure 10 Sites classified into four groups according to similarities in their species composition. Dendrogram partition structure to the four group level is displayed. combination of $Q$ and $F_{\text {peak }}$ with foraging strategy. For instance, fast-flying species that foraged in open airspace are characterised by having lowfrequency echolocation calls that are less attenuated by the atmosphere, while species that hunt in clutter have airframes adapted for slower but more manoeuvrable flight, and use higher-frequency echolocation that sacrifices detection-range for detail-in-imagery (see also Simmons 1989; Kingston et al. 1999; McKenzie et al. 2002; McKenzie and Bullen 2003; Wund 2006; Surlykke and Kalko 2008).

\section{Environmental influences on composition}

A number of other studies have concluded that distance to coastline, to ranges with caves/crevices, and to a riparian zone are important factors explaining patterns in the composition of microbat assemblages (Crome and Richards 1988; Williams and Dickman 2004; Milne et al. 2005b).

The coastal factor differentiated the distinctive bat community found in Pilbara mangroves. Caves or crevices provide obligate day-roosts for a range of species, including five that occur in the Pilbara (e.g. Armstrong 2001; van Dyck and Strahan 2008). Well-developed riparian zones provide the most complex, productive vegetation structures found in semi-arid and arid regions such as the landward environments of the Pilbara. Since bats partition airspace according to clutter-levels (e.g. McKenzie and Rolfe 1986; Schnitzler and Kalko 1998; Bullen and McKenzie 2001), it is not surprising that high microbat species diversity has been associated with freshwater bodies such as perennial rivers elsewhere, and that some species are confined to these situations (e.g. Cross 1988; Law et al. 1998; Young and Ford 2000; Seidman and Zabel 2001). Nyctophilus b. daedalus and C. morio are the two species in the Pilbara's landward community that show this particular habitat specificity. Despite their different foraging strategies, both have specialised aerodynamic cleanliness characteristics (Bullen and McKenzie 2007) and/or flight musclemass ratios (Bullen and McKenzie 2004) that require productive foraging niches: $C$. morio because it needs surplus power to perform highly agile turns close to clutter, and $N$. b. daedalus which incurs high energy costs in manoeuvring and hovering at low speeds (Table 8) while gleaning in clutter because of its airframe's high wing loading (5.6 versus $4.7 \mathrm{~N} \mathrm{~m}^{-2}$ for its counterpart, N. g. geoffroyi). Riparian areas provide greater abundances of insects than wooded habitats, and that has been correlated with higher feeding rates (Thomas 1988). Furthermore, bat activity along intermittent streams in California was related to size, being least along small ephemeral examples, especially when the channels were dry (Seidman and Zabel 2001). Well-developed riparian areas also 


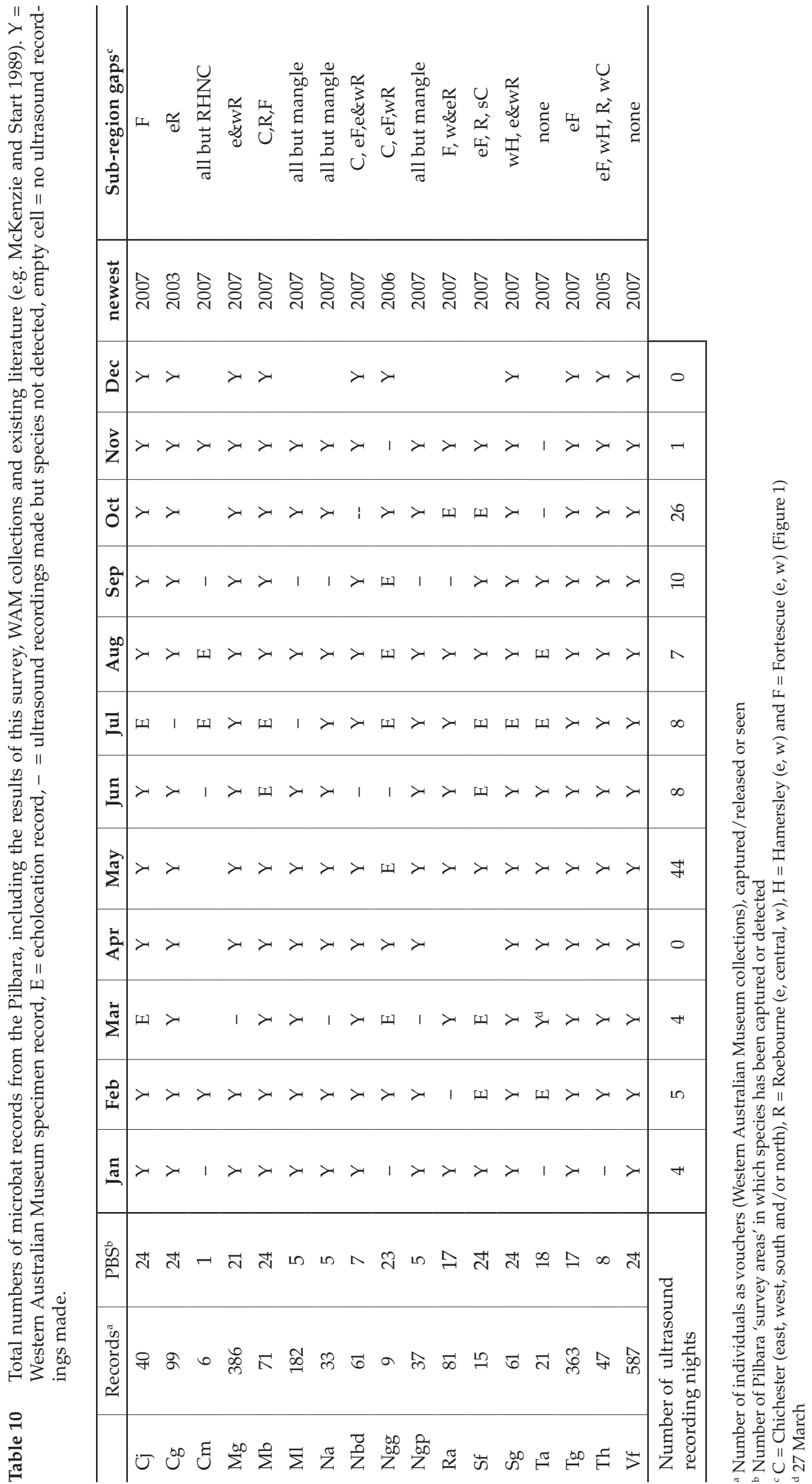



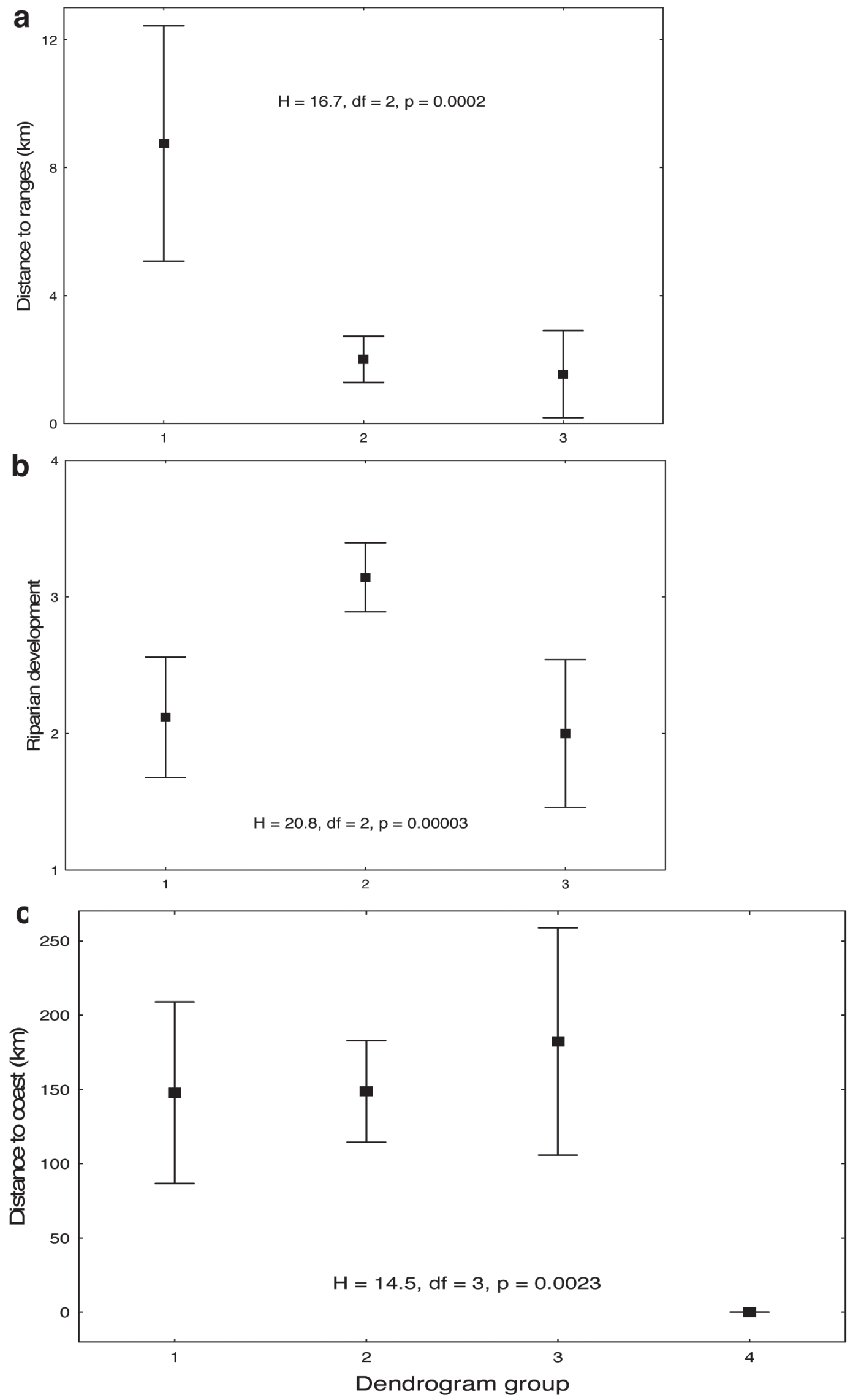

Figure 11 Site attributes that best separated the four dendrogram groups derived from the site classification (Figure 10). In statistical terms, the combination of 'Distance to ranges' and 'Riparian development' separated each of the three landward site-groups, while 'Distanct to coast' separated group-4 (the mangrove sites) from the rest. Mean and $95 \%$ confidence intervals are displayed ( $\mathrm{H}=$ Kruskall-Wallis coefficient). 
provide roost sites and areas for drinking (Cross 1986, 1988; Tidemann and Flavel 1987). Interaction between the 'distance to ranges' and the 'riparian development' factors explained the nestedness in species composition overt in the Pilbara's landward site-groups of Figure 9.

The assemblage analysis herein is based on 2.5 $\mathrm{h}$ recording sessions that commenced at dusk, the period of peak activity for most microbat species (Law et al. 1998; Kuenzi and Morrison 2003; Milne et al. 2005a). Even so, richer species lists might have been achieved from sites that were remote from riparian pools and ranges if the recording sessions had been more prolonged, covering the later parts of the night, and if all sites had been sampled in at least two seasons. Richards (2001) recommended $3 \mathrm{~h}$ of recording from dusk to detect $90 \%$ of species present at a site, and Duffy et al. (2000) recommended $5 \mathrm{~h}$. We averaged 1.9 recording nights, totalling $4.5 \mathrm{~h}$ per site.
In terms of their structural complexity, the regional bat faunas of Western Australia's tropical arid zone conform to a diversity productivity hypothesis (Nijs and Roy 2000), with the most arid regions having species-poor faunas dominated by fast-flying species of open airspace, rather than surface and air superiority strategists that hunt in more cluttered microhabitats (Table 11, also see McKenzie et al. 2002). The Pilbara study confirms that the additional species found in the least arid of these regions are confined to productive landscape mosaics (e.g. C. morio, N. arnhemensis, N. bifax daedalus and M. loriae), or depend on physiologically benign day-roosts in caves and rock-crevices (e.g. M. gigas and R. aurantia; Armstrong 2001). Positive, exponential relationships between productivity and community diversity (richness, evenness and degree of difference between species) are well recognised (e.g. Rosenzweig and Abramski 1993; Srivastrava and Lawton 1998; Nijs and Roy 2000),

Table 11 Structural diversity of microbat faunas in tropical arid regions of Western Australia, listing number of species in each foraging strategy, a measure of overall productivity (annual average rainfall), occurrence of productive landscape mosaics, and availability of physiological refuges (updated from McKenzie et al. 2002). Species codes from Table 1. ${ }^{a} \mathrm{Sb}=$ Scotorepens balstoni (Thomas 1906).

\begin{tabular}{|c|c|c|c|c|c|c|}
\hline Foraging Strategy & Pilbara & Gascoyne & Carnarvon & $\begin{array}{l}\text { Great Sandy } \\
\text { Desert }\end{array}$ & $\begin{array}{l}\text { Little Sandy } \\
\text { Desert }\end{array}$ & $\begin{array}{l}\text { Gibson } \\
\text { Desert }\end{array}$ \\
\hline Interceptor & $\begin{array}{c}\mathrm{Ta} \\
\mathrm{Cj} \\
\mathrm{Mb} \\
\mathrm{Ml} \\
\end{array}$ & $\begin{array}{c}\mathrm{Ta} \\
\mathrm{Cj} \\
\mathrm{Mb}\end{array}$ & $\begin{array}{c}\mathrm{Ta} \\
\mathrm{Cj} \\
\mathrm{Mb} \\
\mathrm{Ml}\end{array}$ & $\begin{array}{c}\mathrm{Ta} \\
\mathrm{Cj} \\
\mathrm{Mb}\end{array}$ & $\begin{array}{c}\mathrm{Ta} \\
\mathrm{Mb}\end{array}$ & $\begin{array}{c}\mathrm{Ta} \\
\mathrm{Mb}\end{array}$ \\
\hline Air Superiority - open & $\begin{array}{l}S f \\
T h \\
T g \\
M l \\
\end{array}$ & $\begin{array}{l}S f \\
T h\end{array}$ & $\begin{array}{l}S f \\
T h \\
M l\end{array}$ & $\begin{array}{l}\text { Sf } \\
\text { Th }\end{array}$ & $\begin{array}{l}\text { Sf } \\
T h\end{array}$ & $T h$ \\
\hline Air Superiority - highly agile & $\begin{array}{l}\mathrm{Cg} \\
\mathrm{Sg} \\
\mathrm{Vf} \\
\mathrm{Ra} \\
\mathrm{Cm}\end{array}$ & $\begin{array}{l}C g \\
S b^{a} \\
V f \\
R a\end{array}$ & $\begin{array}{l}C g \\
S g \\
V f\end{array}$ & $\begin{array}{l}C g \\
S g \\
V f\end{array}$ & $\begin{array}{l}C g \\
S g \\
V f\end{array}$ & $\begin{array}{c}C g \\
S b^{a} \\
V f\end{array}$ \\
\hline Surface - 3-D & $\begin{array}{c}\mathrm{Ngg} \\
\mathrm{Nbd} \\
\mathrm{Na} \\
\mathrm{Ngp}\end{array}$ & $\begin{array}{l}\mathrm{Ngg} \\
\mathrm{Nbd}\end{array}$ & $\begin{array}{c}N g g \\
N a \\
N g p\end{array}$ & $N g g$ & $N g g$ & $N g g$ \\
\hline Surface - ambusher & $M g$ & $M g$ & & & & \\
\hline TOTAL & 17 & 12 & 12 & 9 & 8 & 7 \\
\hline \multicolumn{7}{|l|}{ Productivity } \\
\hline Rainfall (mm) & 350 & 240 & 250 & 240 & 230 & 220 \\
\hline Mangroves & present & none & present & none & none & none \\
\hline Cavernous ranges & widespread & widespread & sparse & rare & rare & rare \\
\hline $\begin{array}{l}\text { Complex riparian woodlands } \\
\text { with permanent pools }\end{array}$ & widespread & widespread & sparse & rare & rare & none \\
\hline
\end{tabular}




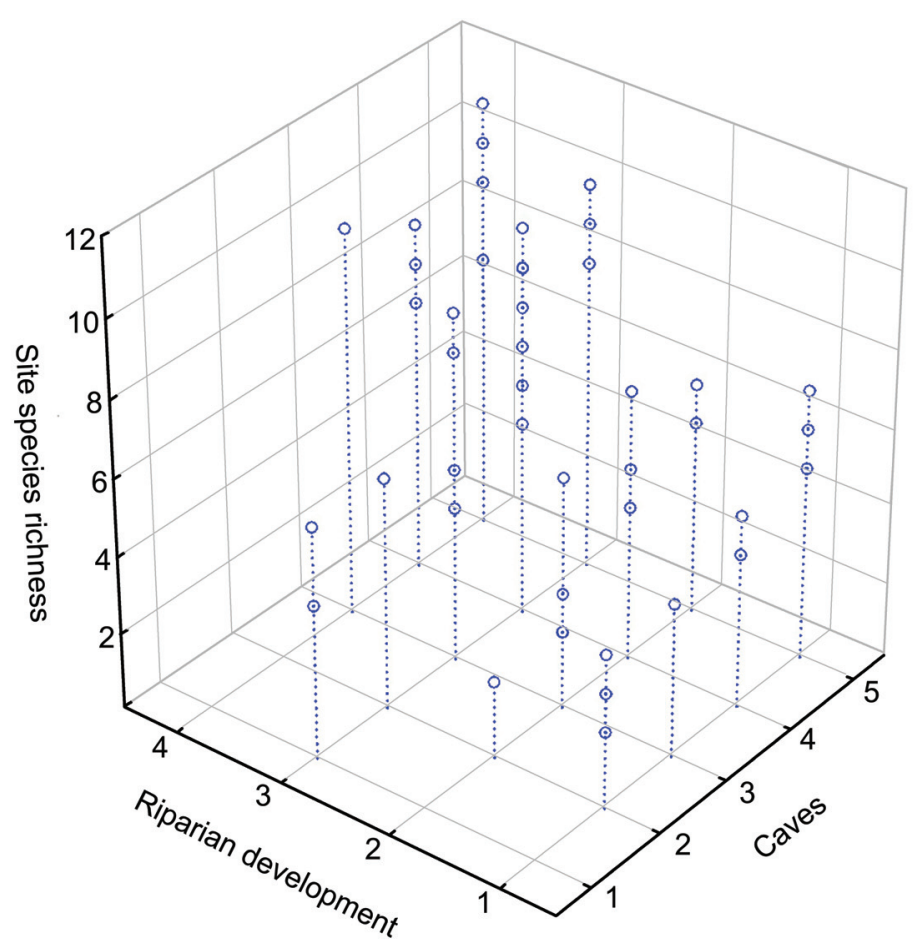

Multiple Correlation $\mathrm{R}(\mathrm{z} / \mathrm{xy})=0.77, \mathrm{p}<0.0001$

Figure 12 Species richness plotted against 'Riparian Development' and 'Caves' (distance to ranges and other cavernous habitat, see Table 2) for the 64 landward sites.

particularly in the context of strong interspecific competition.

\section{Determinants of community structure}

It appears that spectral variables can be used to characterise free-flying bats according to their foraging niche without distorting the outcome by disrupting their normal activities. Spectral variables may allow the organisation of microbat communities to be reliably and quickly related to environmental factors, including disturbance heterogeneity (sensu Urban 2004), even in communities of unknown species composition.

Given the ecological relevance of the spectral variables, the near-regular spacing of species across the spectral plots implies that Pilbara microbat communities are organised deterministically, according to specialisations related to resource partitioning. Niche-assembly models of metacommunity organisation have been reported previously for guilds and faunas of Australian microbats (McKenzie and Rolfe 1986; McKenzie and Start 1989; McKenzie et al. 2002), although these studies used measures of flight capability, rather than echolocation, as surrogates of realised foraging niche. However, this niche-assembly model of metacommunity is insufficient to explain the structure of microbat assemblages at regional scales in the Pilbara because nestedness in assemblage species composition that related to environmental factors was exposed by the habitat analysis, implying the influence of environmental controls (see Mouquet and Loreau 2002; Urban 2004; Armstrong 2005). Several species were absent from those landward sites that were remote from well-developed riparian habitats (e.g. C. morio, N. b. daedalus) while others were absent from the sites that were remote from ranges (e.g. T. georgianus / hilli and $V$. finlaysoni).

Nestedness in species composition was not restricted to the Pilbara's landward community; it was also overt among faunas of the adjacent regions when they were arrayed using rainfall as an approximate measure of regional productivity (Table 11). Where the nestedness was disrupted, the species turnover involved a congeneric replacement (S. greyi by $S$. balstoni in the Gascoyne and Gibson Desert Regions). Equivalent congeneric replacements discriminated the two Pilbara communities: as we noted earlier, three landward species - N. g. geoffroyi, N. bifax daedalus and $M$. beccarii - are replaced in the mangroves by their ecological counterparts $N$. g. pallescens, N. 
arnhemensis and M. loriae, respectively (Table 1). Given the tight relationship between foraging ecology and phylogeny in Western Australian microbats (e.g. McKenzie et al. 2002), we suggest that metacommunity as well as habitat interactions are important determinants of organisation in Western Australian microbats at local and regional scales.

\section{Conservation}

Armstrong (2005) argued that metapopulation and habitat paradigms have to be integrated to understand broad-scale declines in species, and to provide sound management advice. Our study has revealed that metacommunity and habitat paradigms are both required to explain assemblage composition in Pilbara microbats, and we identify several factors relevant to planning for their conservation. Loss of complexity in riparian vegetation, reduced permanence of pools, loss of mangrove stands and loss of suitable cave roosts, are all likely to reduce microbat populations. Any resource development liable to affect these sites should be accompanied by nonintrusive monitoring of microbats; the call library provided in this paper will allow monitoring to be implemented inexpensively. For microbats belonging to the landward community, we need to ensure that well-developed riparian sites in 'range country' are included in conservation reserves (e.g. Weeli Wolli, Cattle Gorge and Turee Creek). For the mangrove bat community, at least five mangrove stands must be included in the conservation reserve system (i.e. Gales Bay, Dampier, Cossack, Balla Balla Harbour and Cape Keraudren); loss of any of these stands will substantially reduce the area of this habitat in the region.

The valley of Weeli Wolli Spring appears to be regionally unique from a microbat viewpoint. It supports the richest microbat assemblage recorded during our survey, and is also the only area in northern Western Australia known to support a population of C. morio (Young et al. 2008). Additionally, data presented herein make it the only location known in northern Western Australia where T. australis can persist through the hot and humid summer months (see Bullen and McKenzie 2005). We speculate that occasional cool air that floods through the Weeli Wolli valley during summer nights may reduce atmospheric enthalpy to levels at which this otherwise temperate-adapted species can forage for long enough to meet its metabolic requirement. Atmospheric enthalpy represents the variation in the combination of temperature, specific humidity and pressure of air.

Pilbara microbats have not yet suffered the extinctions experienced by the region's other (non- volant) indigenous mammals (McKenzie et al. 2006; Baynes and McDowell 2011). We found no evidence that microbat species have been extirpated from parts of the Pilbara; even the 'whispering' bats (so-called because of their seemingly weak call) were recorded in all sub-regions where appropriate habitats were present ( $R$. aurantia, $M$. gigas and Nyctophilus spp.). Nevertheless, a smart reserve system is required to preserve these intact, interesting microbat communities.

\section{ACKNOWLEDGEMENTS}

We thank A.H. Burbidge, P.G. Kendrick, L.A. Gibson, M.H. McKenzie, D.J. Pearson, K.D. Morris, T. Smith and A.N. Start for assisting with field sampling, D.B. McKenzie for the loan of the video camera and P. Doughty and two anonymous referees for helpful comments on the manuscript. M.R. Williams carried out the nestedness and spatial autocorrelation analyses, and N. Babaii compiled Figure 1. Funding for the fieldwork was provided by the Western Australian Department of Environment and Conservation.

\section{REFERENCES}

Armstrong, D.P. (2005). Integrating the metapopulation and habitat paradigms for understanding broadscale declines of species. Conservation Biology 19: 1402-1410.

Armstrong, K.N. (2001). The distribution and roost habitat of the orange leaf-nosed bat, Rhinonicteris aurantius, in the Pilbara region of Western Australia. Wildlife Research 28: 95-104.

Atmar, W. and Patterson, B.D. (1993). The measure of order and disorder in the distribution of species in fragmented habitat. Oecologia 96: 373-382.

Atmar, W. and Patterson, B.D. (1995). The nestedness temperature calculator: a visual basic program, including 294 presence-absence matrices. AICS Research, Inc., University Park: New Mexico, and the Field Museum: Chicago, U.S.A.

Austin, M.P. (1991). Vegetation theory in relation to costefficient survey (pp 17-22). In: Margules, C.R. and Austin, M.P. (eds), Nature conservation: cost effective biological surveys and data analysis. CSIRO Division of Wildlife and Ecology: Canberra, Australia.

Austin, M.P. and McKenzie, N.J. (1988). Data analysis (pp 210-232). In: Gunn, R.H., Beattie, J.A., Reid, R.E. and van der Graaff, R.H.M. (eds), Australian soil and land survey handbook: guidelines for conducting surveys. Inkata Press: Melbourne and Sydney, Australia.

Barclay, M.R., Fullard, J.H. and Jacobs, D.S. (1999). Variation in the echolocation calls of the hoary bat (Lasiurus cinereus): influence of body size, habitat structure and geographic location. Journal of Zoology 77: 530-534.

Baynes, A. (2011). The original mammal fauna of the Pilbara biogeographic region of north-western Australia. Records of the Western Australian Museum, 
Supplement 78 (1): 285-298.

Beard, J.S. (1990). Plant life of Western Australia. Kangaroo Press: Kenthurst, Australia.

Belbin, L. (1980). TWOSTEP: a program incorporating asymmetric comparisons that uses two steps to produce a dissimilarity matrix. CSIRO Division of Land Use Research Technical Memorandum 80/9. CSIRO: Canberra, Australia.

Belbin, L. (1995). PATN technical reference. CSIRO Division of Wildlife and Ecology: Canberra, Australia.

Buchler, E.R. (1976). A chemiluminescent tag for tracking bats and other small nocturnal animals. Journal of Mammalogy 57: 173-176.

Bullen, R.D. and McKenzie, N.L. (2001). Bat airframe design - flight performance, stability and control in relation to foraging ecology. Australian Journal of Zoology 49: 235-261.

Bullen, R.D. and McKenzie, N.L. (2002a). Differentiating Western Australian Nyctophilus (Chiroptera: Vespertilionidae) echolocation calls. Australian Mammalogy 23: 89-93.

Bullen, R.D. and McKenzie, N.L. (2002b). Scaling bat wing-beat frequency and amplitude. Journal of Experimental Biology 205: 2615-2626.

Bullen, R.D. and McKenzie, N.L. (2004). Bat flight muscle mass: implications for foraging strategy. Australian Journal of Zoology 52: 605-622.

Bullen, R.D. and McKenzie, N.L. (2005). Seasonal range variation of Tadarida australis (Chiroptera: Molossidae) in Western Australia: the impact of enthalpy. Australian Journal of Zoology 53: 145-156.

Bullen, R.D. and McKenzie, N.L. (2007). Bat wing airfoil and planform structures relating to aerodynamic cleanliness. Australian Journal of Zoology 55: 237-247.

Casseday, J.H. and Covey, E. (1992). Frequency tuning properties of neurones in the inferior colliculus of an FM bat. The Journal of Comparative Neurology 319: 34-50.

Chao, A. (1987). Estimating the population size for capture-recapture data with un-equal catchability. Biometrics 43: 783-791.

Churchill, S. (1998). Australian bats. Reed New Holland: Sydney, Australia.

Clarke, K.R. (1993). Non-parametric multivariate analyses of changes in community structure. Australian Journal of Ecology 6: 163-174.

Clarke, K.R. and Green, R.H. (1988). Statistical design and analysis for a 'biological effects' study. Marine Ecology Progress Series 46: 213-226.

Colwell, R.K. (2006). EstimateS. Statistical estimation of species richness and shared species from samples Version 8.0. http:/ / viceroy.eeb.uconn.edu/estimates

Crome, F.H.J. and Richards, G.C. (1988). Bats and gaps: microchiropteran community structure in a Queensland rain forest. Ecology 69: 1960-1969.

Cross, S.P. (1986). Bats (pp 279-519). In: Cooperrider, A.Y., Boyd, R.J. and Stuart, H.R. (eds), Inventory and monitoring of wildlife habitat. United States Department of Interior, Bureau of Land Management Service Center: Colorado, U.S.A.

Cross, S.P. (1988). Riparian systems and small mammals and bats (pp 93-112). In: Raedeke, K.J. (ed.), Streamside management: riparian wildlife and forestry interactions.
University of Washington Institute of Forest Resources Contribution 59: 1-277. Washington, U.S.A.

Dickman, C. and Crowther, M. (2009). Science and the environment (pp 23-42). In: Calver, M.C., Lymbery, A., McComb, J. and Bamford, M. (eds), Environmental biology. Cambridge University Press: Cambridge, U.K.

Diniz-Filho, J.A.F., Bini, L.M. and Hawkins, B.A. (2003). Spatial autocorrelation and red herrings in geograhical ecology. Global Ecology and Biogeography 12, 53-64.

Duffy, A.M., Lumsden, L., Caddle, C.R., Chick, R.R. and Newell, G.R. (2000). The efficacy of Anabat ultrasonic detectors and harp traps for surveying microchiropterans in South-eastern Australia. ACTA Chiropterologica 2: 127-144.

Environment Australia (2000). Revision of the Interim Biogeographic Regionalisation of Australia (IBRA) and development of version 5.1. Environment Australia: Canberra, Australia.

Gannon, W.L., Sherwin, R.E. and Haymond, S. (2003). On the importance of articulating assumptions when conducting acoustic studies of habitat use by bats. Wildlife Society Bulletin 31: 45-61.

Griffin, D.R., Webster, F.A. and Michael, C.R. (1960). The echolocation of flying insects by bats. Animal Behaviour 8: 141-154.

Guppy, A. and Coles, R.B. (1988). Acoustical aspects of hearing and echolocation in bats (pp 289-294). In: Nachtigall, P.E. and Moore, P.W.B. (eds), Animal sonar. Plenum Press: New York, U.S.A.

Hall, L., Richards, G., McKenzie, N. and Dunlop, N. (1997). The importance of abandoned mines as habitat for bats (pp 326-333). In: Hales, P. and Lamb, D. (eds), Conservation outside nature reserves. Centre for Conservation Biology, The University of Queensland: Brisbane, Australia.

Heller, K-G. and Helversen, Ov. (1989). Resource partitioning of sonar frequency bands in rhinolophoid bats. Oecologia 80: 178-186.

Hernández, L., Romero, A.G., Laundré, J.W., Lightfoot, D., Aragón, E. and López Portillo, J. (2005). Changes in rodent community structure in the Chihuahuan Desert, México: comparisons between two habitats. Journal of Arid Environments 60: 239-257.

Hespenheide, H.A. (1975). Prey characteristics and predator niche width (pp 158-180). In: Cody, M.L. and Diamond, J.M. (eds), Ecology and evolution of communities. Belknap Press: Cambridge: Massachusetts, U.S.A.

Kalko, E.K.V. and Schnitzler, H.U. (1993). Plasticity in echolocation signals of European pipistrelle bats in search flight: implications for habitat-use and prey detection. Behavioural Ecology and Sociobiology 33: 415-428.

Kalko, E.K.V. and Schnitzler, H.U. (1998). How echolocating bats approach and acquire food (pp 197-204). In: Kunz, T.H. and Racey, P.A. (eds), Bat biology and conservation. Smithsonian Institution Press: Washington, U.S.A.

Kingston, T.G., Jones, G., Akbar, Z. and Kunz, T.H. (1999). Echolocation signal call design in Kerivoulinae and Murininae (Chiroptera: Vespertilionidae) from Malaysia. 
Journal of Zoology (London) 249: 359-374.

Kuenzi, A.J. and Morrison, M.L. (2003). Temporal patterns of bat activity in southern Arizona. Journal of Wildlife Management 67: 52-64.

Kulzer, E., Nelsen, J.E., McKean, J.L. and Moehres, F.P. (1984). Prey-catching behaviour and echolocation in the Australian Ghost Bat (Macroderma gigas) (Microchiroptera: Megadermatidae). Australian Mammalogy 7: 37-50.

Laverghetta, T.S. (1981). Handbook of microwave testing. Artech: Dedham, U.S.A.

Law, B., Anderson, J. and Chidel, M. (1998). A bat survey in state forests on the south-west slopes region of New South Wales with suggestions of improvements for future surveys. Australian Zoologist 30: 467-479.

Lee, S.M. and Chao, A. (1994). Estimating population size via sample coverage for closed capture-recapture models. Biometrics 50: 88-97.

Lumsden, L.F. and Bennett, A.F. (1995). Bats of a semi-arid environment in south-eastern Australia: biogeography, ecology and conservation. Wildlife Research 22: 217-240.

McKenzie, N.L. and Bullen, R.D. (2003). Identifying Little Sandy Desert bat species from their echolocation calls. Australian Mammalogy 25: 73-80.

McKenzie, N.L., Burbidge, A.A., Baynes, A., Brereton, R., Dickman, C.R., Gibson, L.A., Gordon, G., Menkhorst, R.W., Robinson, A.C., Williams, M.R. and Woinarski, J.C.Z. (2006). Analysis of factors implicated in the recent decline of Australia's mammalian fauna. Journal of Biogeography 34: 597-611.

McKenzie, N.L. and Churchill, S.K. (2008). Northern Long-eared Bat Nyctophilus arnhemensis Johnson 1959 (pp 516-517). In: van Dyke, S. and Strahan, R. (eds), The mammals of Australia. $3^{\text {rd }}$ edition. Reed New Holland: Sydney, Australia.

McKenzie, N.L. and Muir, W.P. (2000). Bats of the southern Carnarvon Basin, Western Australia. Records of the Western Australian Museum, Supplement 61: 465-477.

McKenzie, N.L. and Rolfe, J.K. (1986). Structure of bat guilds in the Kimberley mangroves, Australia. Journal of Animal Ecology 55: 401-420.

McKenzie, N.L. and Start, A.N. (1989). Structure of bat guilds in mangroves: disturbance and determinism (pp 167-178). In: Morris, D.W., Abramski, Z., Fox, B.J. and Willig, M.R. (eds), Patterns in the structure of mammalian communities. Special Publication, Texas Technical University: Lubbock, U.S.A.

McKenzie, N.L., Start, A.N. and Bullen, R.D. (2002). Foraging ecology and organization of a desert bat fauna. Australian Journal of Zoology 50: 529-548.

McKenzie, N.L., van Leeuwen, S. and Pinder, A.M. (2009). Introduction to the Pilbara biodiversity survey, 2002-2007. Records of the Western Australain Museum, Supplement 78 (1): 3-89.

McMahon, J.P., Hutchinson, M.F., Nix, H.A. and Ord, K.D. (1995). ANUCLIM users guide. Version 1. Centre for Resource and Environmental Studies, Australian National University: Canberra, Australia.

McNab, B.K. (1980). Food-habits, energetics, and the population biology of mammals. The American
Naturalist 116: 106-124.

Meynard, C.N. and Quinn, J.F. (2007). Predicting species distributions: a critical comparison of the most common statistical models using artificial species. Journal of Biogeography 34: 1455-1469.

Milne, D.J. (2002). Key to the bat calls of the Top End of the Northern Territory. Technical Report No. 71. Parks and Wildlife Commission: Darwin, Australia.

Milne, D.J., Armstrong, A., Fisher, A., Flores, T. and Pavey, C.R. (2005b). Structure and environmental relationships of insectivorous bat assemblages in tropical Australian savannas. Austral Ecology 30: 914-927.

Milne, D.J., Fisher, A., Rainey, I. and Pavey, C.R. (2005a). Temporal patterns of bats in the top end of the Northern Territory, Australia. Journal of Mammalogy 86: 909-920.

Mouquet, N. and Loreau, M. (2002). Coexistence in metacommunities: the regional similarity hypothesis. The American Naturalist 159: 420-426.

Murray, K.L., Britzke, E.R. and Robbins, L.W. (2001). Variation in search-phase calls of bats. Journal of Mammalogy 82: 728-737.

Neuweiler, G. (1990). Auditory adaptations for prey capture in echolocating bats. Physiological Review 70: 615-641.

Nijs, I. and Roy, J. (2000). How important are species richness, species evenness and interspecific differences to productivity? A mathematical model. Oikos 88: 57-66.

Obrist, M.K. (1995). Flexible bat echolocation calls: the influence of individual, habitat and conspecifics on sonar design. Behavioural Ecology and Sociobiology 36: 207219.

Obrist, M.K., Fenton, M.B., Eger, J.L. and Schlegel, P.A. (1993). What ears do for bats: a comparative study of pinna sound pressure transformation in chiroptera. Journal of Experimental Biology 180: 119-152.

O'Farrell, M.J., Miller, B.W. and Gannon, W.L. (1999). Qualitative identification of free-flying bats using the Anabat detector. Journal of Mammalogy 80: 11-23.

Oksanen, L. (2001). Logic of experiments in ecology: is pseudoreplication a pseudoissue? Oikos 94: 27-38.

Parsons, S. (1997). Search-phase echolocation calls of the New Zealand short-tailed bat (Mystacina tuberculata) and long-tailed bat (Chalinolobus tuberculatus). Canadian Journal of Zoology 75: 1487-1494.

Parsons, S., Boonman, A.M. and Obrist, M.K. (2000). Advantages and disadvantages of techniques for transforming and analysing Chiropteran echolocation calls. Journal of Mammalogy 81: 927-938.

Prosser, C.L. and Brown, F. (1961). Comparative animal physiology. W.B. Saunders: Philadelphia, U.S.A.

Richards, G.C. (2001). Towards defining adequate bat survey methodology: why electronic call detection is essential throughout the night. Bat Society Newsletter 16: $24-28$.

Richards, G.C., Hand, S., Armstrong, K.N. and Hall, L.S. (2008). Ghost bat Macroderma gigas (Dobson, 1880) (pp 449-450). In: van Dyke, S. and Strahan, R. (eds), The mammals of Australia. $3^{\text {rd }}$ edition. Reed New Holland: Sydney, Australia. 
Rosenzweig, M.L. and Abramski, Z. (1993). How are diversity and productivity related? (pp 52-65). In: Ricklefs, R.E. and Schluter, D. (eds), Species diversity in ecological communities: historical and geographical perspectives. University of Chicago Press: Chicago, U.S.A.

Schnitzler, H.U. and Kalko, E.K.V. (1998). How echolocating bats search and find food (pp 183-196). In: Kunz, T.H. and Racey, P.A. (eds), Bat biology and conservation. Smithsonian Institution Press: Washington, U.S.A.

Schnitzler, H.U., Kalko, E.K.V. and Surlykke, A. (1987). The echolocation and hunting behaviour of the bat, Pipistrellus kuhli. Journal of Comparative Physiology A 161: 267-274.

Seidman, V.M. and Zabel, C.J. (2001). Bat activity along intermittent streams in northwestern California. Journal of Mammalogy 82: 738-747.

Simberloff, D. and Dyan, T. (1991). The guild concept and the structure of ecological communities. Annual Review of Ecology and Systematics 22: 115-143.

Simmons, J.A. (1989). A view of the world through the bat's ear: the formation of acoustic images in echolocation. Cognition 33: 155-199.

Sneath, P.H.A. and Sokal, R.R. (1973). Numerical taxonomy: the principles and practice of numerical classification. W.H. Freeman: San Francisco, U.S.A.

Spicer, J.I. and Gaston, K. (1999). Physiological diversity and its ecological implications. Blackwell Science: Oxford, U.K.

Srivastrava, D.S. and Lawton J.H. (1998). Why more productive sites have more species: an experimental test of theory using tree-hole communities. The
American Naturalist 152: 510-529.

Surlykke, A. and Kalko, E.K.V. (2008). Echolocating bats cry out loud to detect their prey. PloS ONE 3(4): e2036.

Thomas, D.W. (1988). The distribution of bats in different ages of Douglas-fir forests. Journal of Wildlife Management 52: 619-626.

Thomas, O. (1913). Two new Australian mammals. Annual Magazine of Natural History 11: 79-80.

Tidemann, C.R. and Flavel, S.C. (1987). Factors affecting choice of diurnal roost sites by tree-hole bats (Microchiroptera) in south-eastern Australia. Australian Wildlife Research 14: 459-473.

Urban, M.C. (2004). Disturbance heterogeneity determines freshwater metacommunity structure. Ecology 85: 29712978.

van Dyke, S. and Strahan, R. (eds) (2008). The mammals of Australia. $3^{\text {rd }}$ edition. Reed New Holland: Sydney, Australia.

Williams, A.J. and Dickman, C.R. (2004). The ecology of insectivorous bats in the Simpson Desert, central Australia: habitat use. Australian Mammalogy 26: 205-214.

Wund, M.A. (2006). Variation in the echolocation calls of Little Brown Bats (Myotis lucifugus) in response to different habitats. American Midland Naturalist 156: 99-108.

Young, R.A. and Ford, G.I. (2000). Bat fauna of a semi-arid environment in central western Queensland, Australia. Wildlife Research 27: 203-215.

Young, R.A., Turbill, C., Law, B.S. and Tidemann, C.R. (2008). Chocolate Wattled Bat Chalinolobus morio (Gray, 1841) (pp 535-536). In: van Dyke, S. and Strahan, R. (eds), The mammals of Australia. $3^{\text {rd }}$ edition. Reed New Holland: Sydney, Australia.

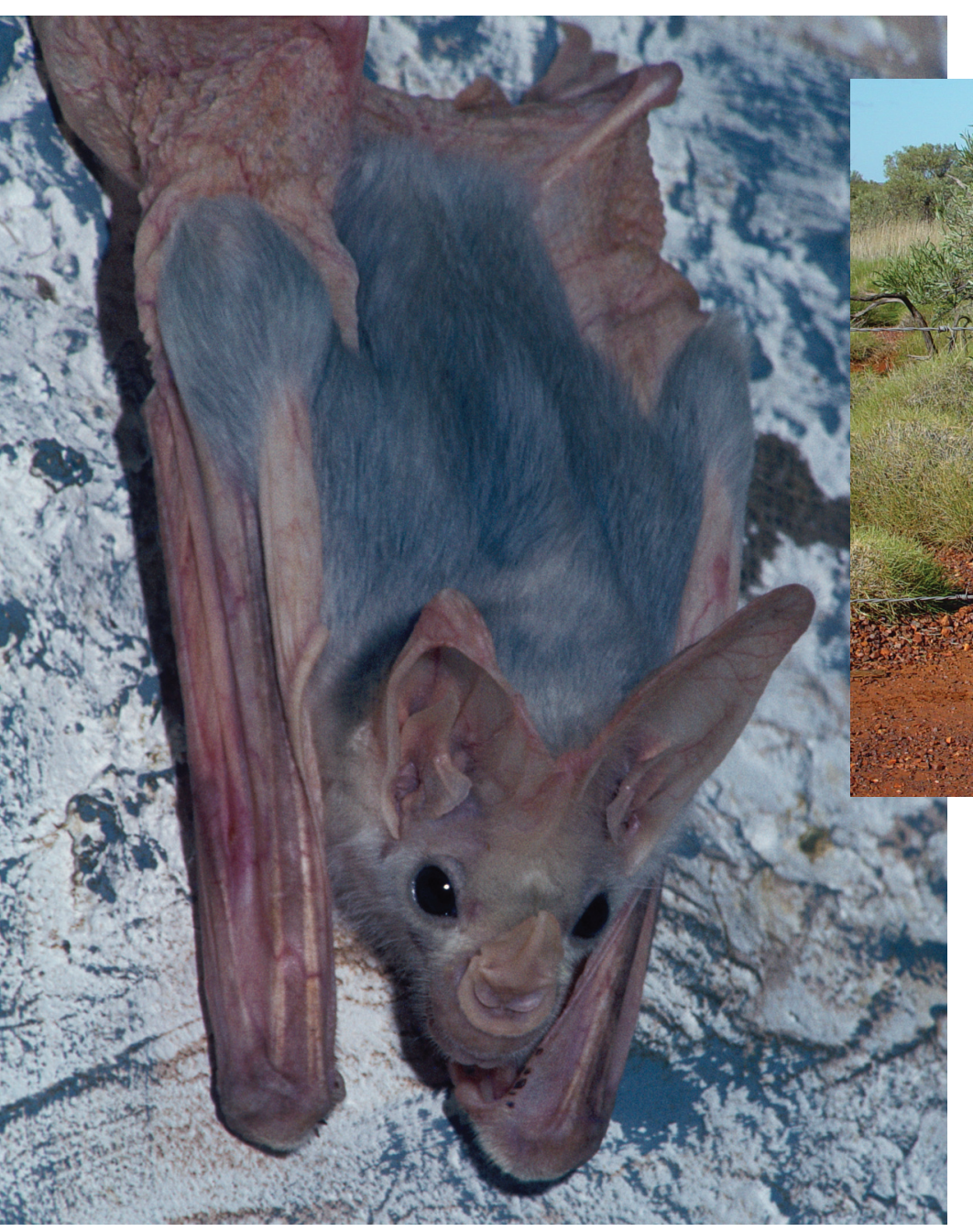

LEFT: Ghost Bat (Macroderma gigas), a monotypic genus endemic in Australia. The Pilbara supports the last arid zone population of this once-widespread, nocturnal predator. The Pilbara form is much paler than the Kimberley population illustrated, and listed as 'Vulnerable' by IUCN (Lochman).

RIGHT: To save energy while commuting, Ghost Bats often fly 'in ground-effect'. Consequently, mummified remains are sometimes found impaled on barbed wire fences. (N.L. McKenzie). 


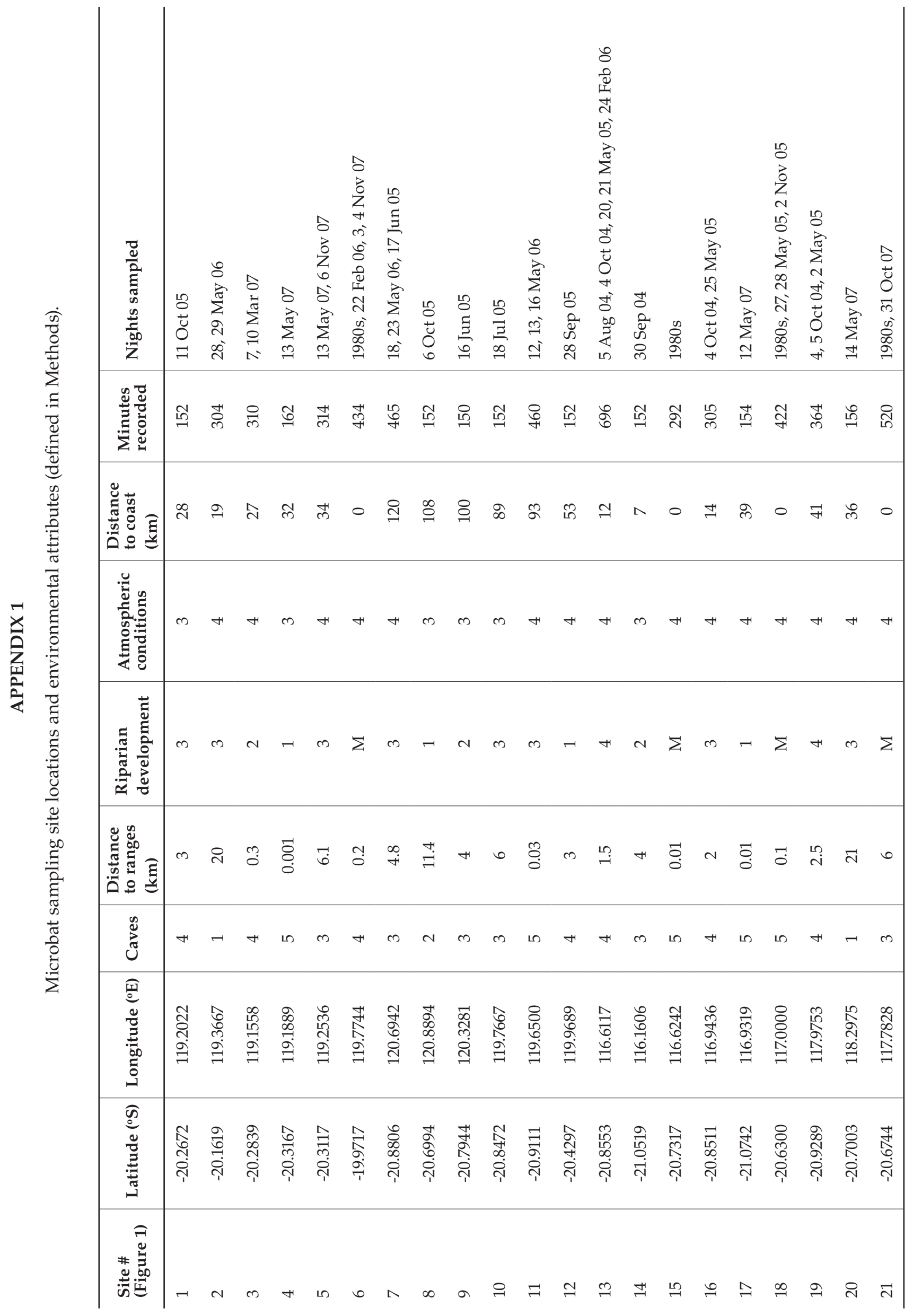




\begin{tabular}{|c|c|c|c|c|c|c|c|c|c|c|c|c|c|c|c|c|c|c|c|c|c|c|c|}
\hline 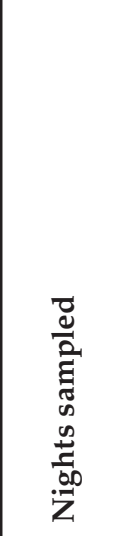 & 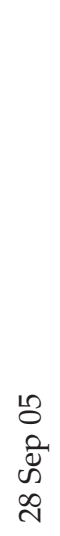 & 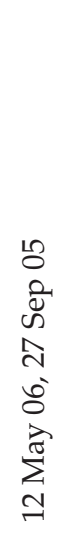 & $\begin{array}{l}\infty \\
\infty \\
\stackrel{\infty}{\sigma}\end{array}$ & $\begin{array}{l}\qquad 8 \\
\vec{U} \\
0 \\
0\end{array}$ & 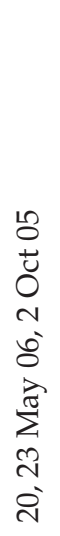 & $\begin{array}{l}\text { 며 } \\
\vdots \\
\vdots \\
\sigma\end{array}$ & 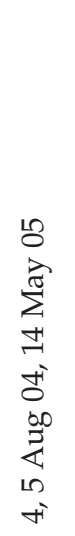 & 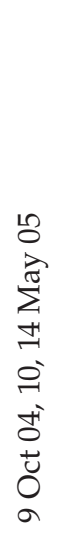 & 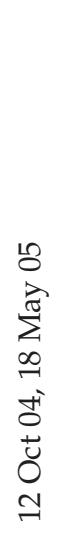 & $\begin{array}{l}\text { L } \\
0 \\
\sum_{0}^{\pi} \\
0\end{array}$ & 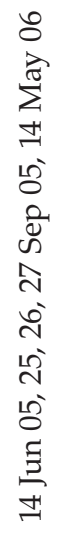 & 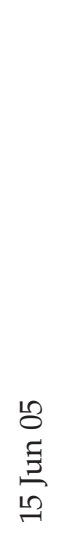 & 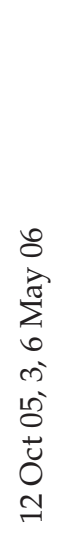 & $\begin{array}{l}\stackrel{2}{0} \\
\Xi \\
\Xi \\
\exists\end{array}$ & $\begin{array}{l}\stackrel{ }{O} \\
\Xi \\
\stackrel{\Xi}{0}\end{array}$ & 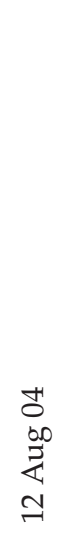 & 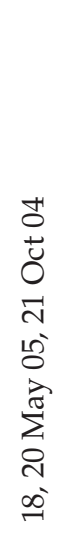 & 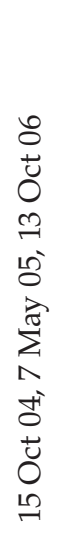 & $\begin{array}{l}8 \\
\frac{8}{3} \\
0 \\
0\end{array}$ & $\begin{array}{l}\text { L) } \\
\text { aे } \\
\omega \\
m\end{array}$ & $\begin{array}{l}\text { 오 } \\
\dot{U} \\
0 \\
a\end{array}$ & $\begin{array}{l}8 \\
8 \\
0 \\
0 \\
1 \\
4 \\
0 \\
0\end{array}$ & 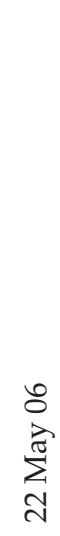 \\
\hline 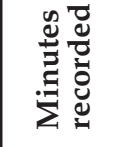 & $\stackrel{\text { 吊 }}{n}$ & ટ్ల & ปิ & กิ & 总 & $\stackrel{\text { 足 }}{\curvearrowleft}$ & $\begin{array}{l}\qquad \begin{array}{l}\infty \\
\infty \\
\infty\end{array}\end{array}$ & 学 & ફ્లి & กิ & 余 & 号 & 草 & $\stackrel{\mathscr{n}}{\mathscr{n}}$ & $\stackrel{\circ}{\circ}$ & 号 & 余 & 占 & กิ & 兽 & $\stackrel{8}{\circ}$ & ర్రి & 总 \\
\hline 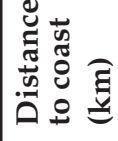 & F & ה & 0 & $\stackrel{\varrho}{\circ}$ & $\infty$ & $\stackrel{m}{=}$ & $\stackrel{\infty}{\sigma}$ & 6 & 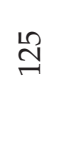 & Aิ & ఘ & สू & $\vec{m}$ & $\exists$ & $\stackrel{\widehat{m}}{\stackrel{-}{n}}$ & స్సి & ڤ્సે & : & $\stackrel{\mathscr{n}}{n}$ & ర్లి & $\stackrel{\infty}{m}$ & $\vec{ర}$ & $\stackrel{\infty}{\text { ले }}$ \\
\hline 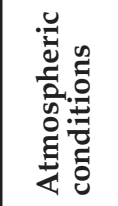 & $\infty$ & $m$ & $H$ & $\infty$ & $H$ & - & $m$ & $H$ & $m$ & $m$ & $H$ & $N$ & $m$ & $m$ & $N$ & $N$ & $m$ & $H$ & $N$ & $H$ & $H$ & $r$ & 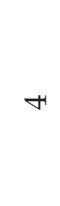 \\
\hline 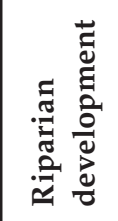 & $\infty$ & $m$ & $\Sigma$ & $r$ & $\psi$ & $N$ & $H$ & $\infty$ & $N$ & $m$ & $m$ & $N$ & $m$ & $N$ & $N$ & $N$ & $m$ & $m$ & $m$ & - & $H$ & $H$ & $m$ \\
\hline 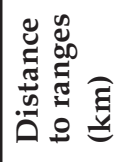 & n & $\underset{+}{+}$ & రి & $\stackrel{\overbrace{}}{\varrho}$ & הี & $\stackrel{\text { LO }}{0}$ & $N$ & $\stackrel{0}{0}$ & ळे & N & $\stackrel{\overbrace{}}{\circ}$ & $\stackrel{\circ}{+}$ & กֶ. & $\stackrel{\leftrightarrow}{-}$ & $\stackrel{\circ}{\circ}$ & $\stackrel{\text { Pִ }}{\longrightarrow}$ & ชู & $\stackrel{\infty}{\circ}$ & $N$ & $\stackrel{12}{\sim}$ & 0 & $\dot{o}$ & $\stackrel{\circ}{\circ}$ \\
\hline 苞 & $m$ & - & $\infty$ & N & $\psi$ & n & H & $1 n$ & $m$ & $r$ & $H$ & $\infty$ & H & $H$ & $m$ & H & $r$ & H & H & $N$ & $m$ & r & $m$ \\
\hline 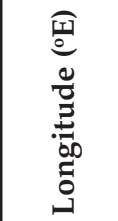 & 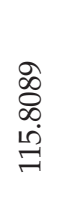 & $\begin{array}{l}\infty \\
0 \\
9 \\
9 \\
10 \\
=\end{array}$ & 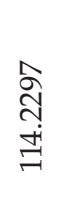 & 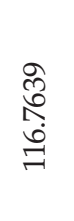 & 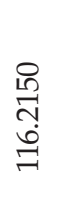 & 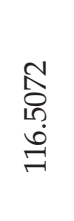 & 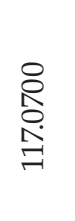 & 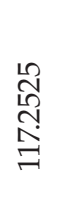 & $\begin{array}{l}\hat{\vec{D}} \\
\infty \\
\stackrel{0}{\exists} \\
\Rightarrow\end{array}$ & $\begin{array}{l}\text { ठิ } \\
\text { ડેे } \\
\exists\end{array}$ & 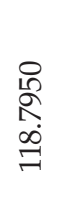 & $\begin{array}{l}10 \\
\infty \\
\infty \\
\infty \\
\infty \\
\exists\end{array}$ & $\begin{array}{l}\infty \\
\infty \\
0 \\
\stackrel{0}{0} \\
\stackrel{\Xi}{=}\end{array}$ & 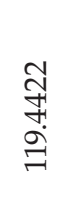 & 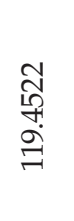 & 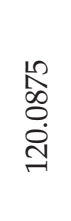 & 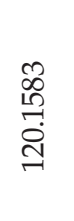 & 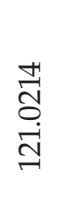 & $\begin{array}{l}\text { Iี } \\
\text { के } \\
\text { तิ }\end{array}$ & 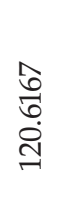 & 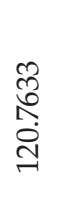 & 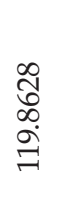 & 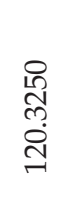 \\
\hline 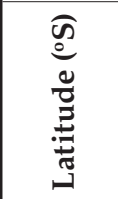 & $\begin{array}{l}\stackrel{\infty}{\infty} \\
\stackrel{N}{1} \\
\vec{i}\end{array}$ & 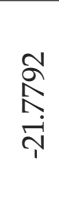 & 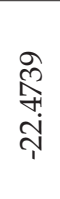 & 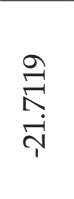 & $\begin{array}{l}\stackrel{\infty}{\infty} \\
\stackrel{+}{i}\end{array}$ & 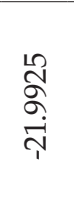 & 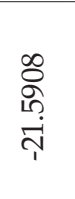 & $\begin{array}{l}\infty \\
\infty \\
\infty \\
\infty \\
\end{array}$ & $\begin{array}{l}\hat{\sigma} \\
\overrightarrow{\widehat{T}} \\
\vec{\uparrow}\end{array}$ & $\begin{array}{l}\stackrel{3}{\aleph} \\
\stackrel{\hat{N}}{i} \\
\stackrel{1}{1}\end{array}$ & 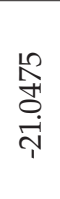 & 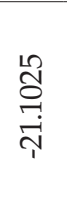 & 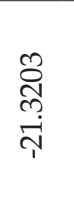 & $\begin{array}{l}\overrightarrow{0} \\
\stackrel{0}{0} \\
\vec{i}\end{array}$ & 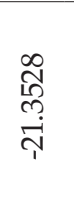 & $\begin{array}{l}\stackrel{2}{N} \\
\stackrel{\infty}{0} \\
\vec{T}\end{array}$ & 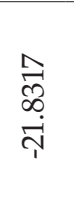 & $\begin{array}{l}0 \\
\stackrel{0}{0} \\
\text { ָे } \\
\stackrel{1}{1}\end{array}$ & $\begin{array}{l}\overrightarrow{\widetilde{V}} \\
\underset{i}{T} \\
\vec{i}\end{array}$ & $\begin{array}{l}\text { Fे } \\
\text { ते } \\
\text { ì }\end{array}$ & 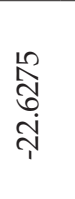 & 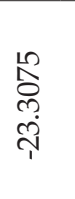 & 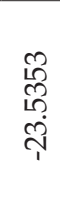 \\
\hline 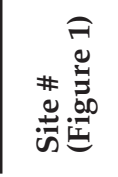 & तี & $\stackrel{\sim}{\sim}$ & $\overleftrightarrow{N}$ & $\stackrel{\stackrel{2}{N}}{ }$ & $\stackrel{\sim}{\sim}$ & ते & $\stackrel{\infty}{N}$ & ৯े & ले & $\vec{m}$ & లు & $m$ & ले & $\stackrel{\mathscr{m}}{m}$ & లి & ले & $\stackrel{\infty}{\infty}$ & ले & 아 & F & F & F & $F$ \\
\hline
\end{tabular}




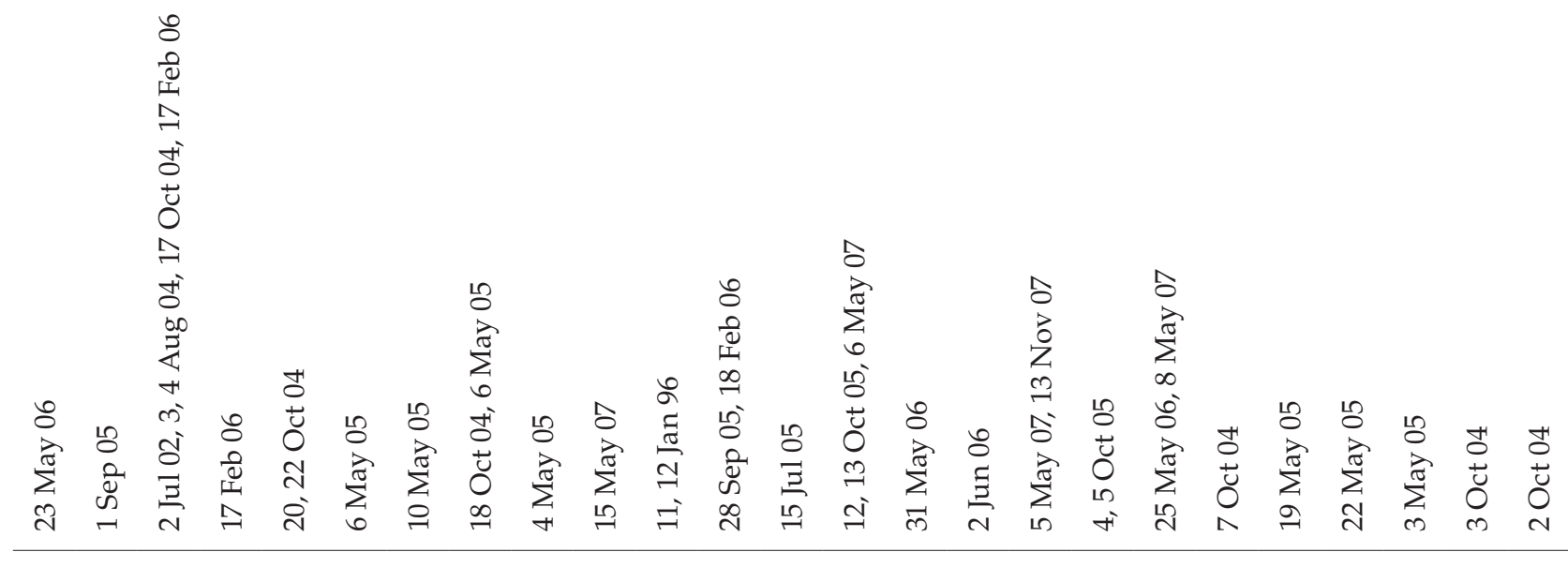

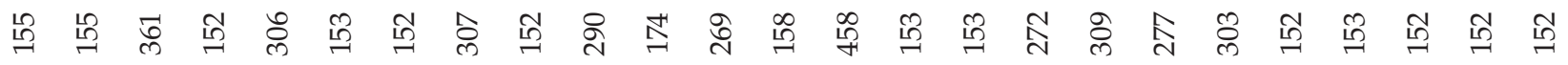

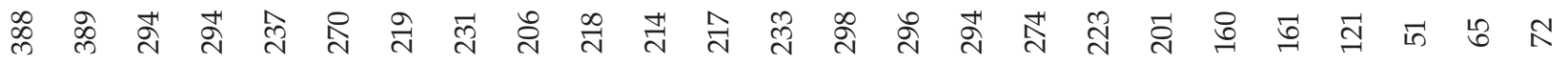

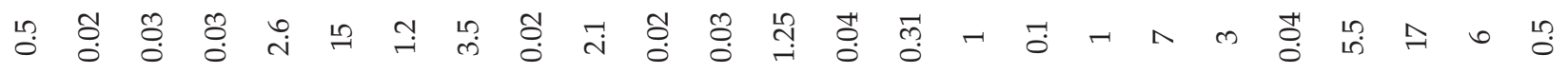

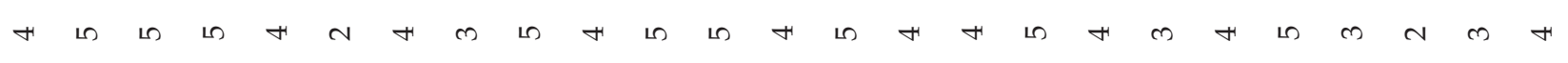

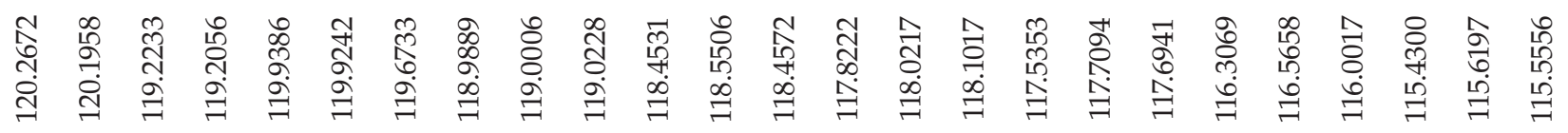

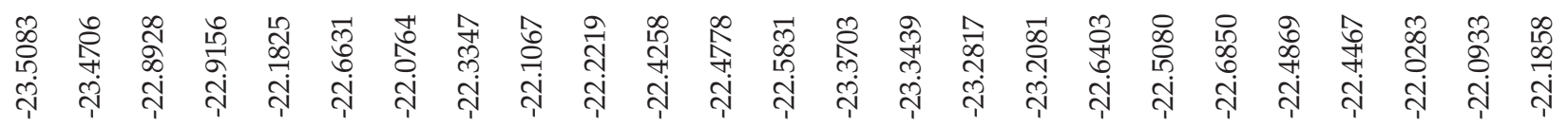

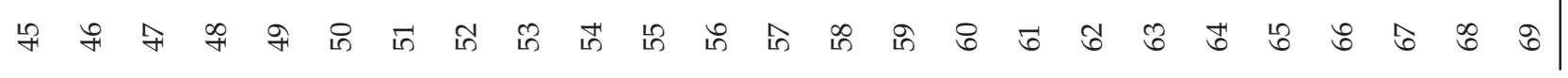

